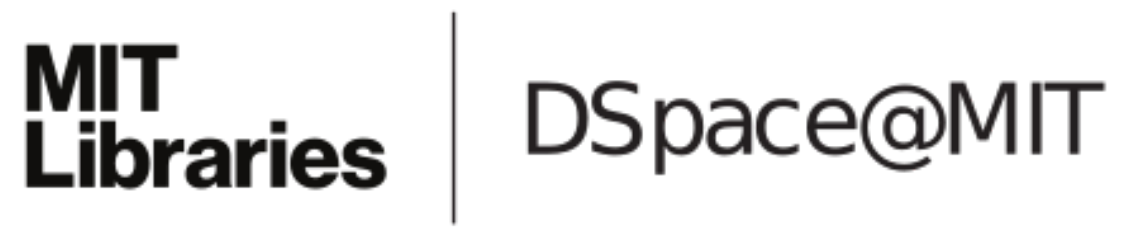

\author{
MIT Open Access Articles
}

A Clock Reaction Based on Molybdenum Blue

The MIT Faculty has made this article openly available. Please share how this access benefits you. Your story matters.

Citation: Neuenschwander, Ulrich, Arnaldo Negron, and Klavs F. Jensen. "A Clock Reaction Based on Molybdenum Blue." The Journal of Physical Chemistry A 117, no. 21 (May 30, 2013): 4343-4351.

As Published: http://dx.doi.org/10.1021/jp400879d

Publisher: American Chemical Society (ACS)

Persistent URL: http://hdl.handle.net/1721.1/92773

Version: Author's final manuscript: final author's manuscript post peer review, without publisher's formatting or copy editing

Terms of Use: Article is made available in accordance with the publisher's policy and may be subject to US copyright law. Please refer to the publisher's site for terms of use. 


\title{
A Clock Reaction Based on Molybdenum Blue
}

\author{
Ulrich Neuenschwander, Arnaldo Negron, Klavs F. Jensen* \\ Department of Chemical Engineering, Massachusetts Institute of Technology, \\ 77 Massachusetts Avenue, Cambridge MA 02139, USA.
}

\begin{abstract}
Clock reactions are rare kinetic phenomena, so far limited mostly to systems with ionic oxoacids and oxoanions in water. We report a new clock reaction in cyclohexanol that forms molybdenum blue from a non-charged, yellow molybdenum complex as precursor, in the presence of hydrogen peroxide. Interestingly, the concomitant color change is reversible, enabling multiple clock cycles to be executed consecutively. The kinetics of the clock reaction were experimentally characterized, and by adding insights from quantum chemical calculations, a plausible reaction mechanism was postulated. Key elementary reaction steps comprise sigmatropic rearrangements with five-membered or bicyclo[3.1.0] transition states. Importantly, numerical kinetic modeling demonstrated the mechanism's ability to reproduce the experimental findings. It also revealed that clock behavior is intimately connected to the sudden exhaustion of hydrogen peroxide. Due to the stoichiometric coproduction of ketone, the reaction bears potential for application in alcohol oxidation catalysis.
\end{abstract}

Keywords: nonlinear phenomena - kinetics - metal catalysis - mechanism 


\section{INTRODUCTION}

Clock reactions are defined as chemical systems in which abrupt concentration changes occur after a well-defined, sharp induction time. ${ }^{1}$ These reactions are rare, since under most conditions, gradual and steady concentration changes are observed. The most famous example is Landolt's iodine clock, ${ }^{2}$ which is based on dark $\mathrm{I}_{3}{ }^{-}$intermediates that are instantaneously quenched by a reducing agent, until the latter is consumed. ${ }^{3}$ A nice summary of all variants of the Landolt clock reaction was given by Oliveira and Faria. ${ }^{4}$ They also listed the other known clock reactions, all based on aqueous redox chemistry using ionic reagents, mostly oxoacids and oxoanions. The study of the nonlinear kinetics of clock reactions is important to understand the basics of other nonlinear effects, such as oscillatory behavior in catalytic fixed bed reactors ${ }^{5}$ or chiral amplification in stereoselective synthesis. ${ }^{6}$ Indeed, several clock reactions could be successfully triggered to undergo oscillations. ${ }^{4,7}$ In this regard, the clock reactions are phenomenologically similar to the classical chemical oscillators, as described by Belousov-Zhabotinsky, ${ }^{8}$ BrayLiebhafsky ${ }^{9}$ and Briggs-Rauscher. ${ }^{10}$ It is generally accepted that clock reactions share a common kinetic feature: The induction time marks the point in the course of a reaction, where one inhibitory component has been fully consumed. ${ }^{1}$ Thus, the sudden buildup of a certain product is possible. In the case of Landolt's iodine clock, autocatalysis has been found to further speed up the clock transition. ${ }^{4}$

Organic-soluble molybdenum(VI) complexes are well-studied, high-performance oxidation catalysts. Their prime application is heterolytic (i.e. non-radical) Sharpless-like activation of hydroperoxides for the epoxidation of olefins. ${ }^{11}$ For a long time it has been known that in these epoxidation systems also radicals can be formed (i.e. homolytic activation of hydroperoxides), 
leading to allylic byproducts. ${ }^{12}$ Recently, the mechanism of radical formation was revealed, showing that Sharpless-like oxidation of hydroperoxide can occur, leading to homolytically labile trioxide intermediates. ${ }^{13}$ This undesired side-reaction has a transition state with a welldefined bicyclo[3.1.0] structure, and belongs to the class of sigmatropic rearrangements. For synthetic purposes, the epoxidations are typically based on tertiary hydroperoxides, in order to prevent further complications arising from oxidation of the hydroperoxide's geminal hydrogen. Some studies include experiments with hydrogen peroxide as the oxidant, but this approach is generally not very successful, due to low turnover. ${ }^{14}$ However, there is consensus that in this case, $\eta^{2}$-peroxo intermediates are the active species. ${ }^{15}$

Molybdenum blue (MB) is the name of a family of compounds that are characterized by partially reduced molybdenum oxide hydroxide clusters $\left\{\mathrm{Mo}_{\mathrm{w}}{ }^{\mathrm{VI}} \mathrm{Mo}^{\mathrm{V}} \mathrm{O}_{\mathrm{y}} \mathrm{H}_{z}\right\}^{\mathrm{n}-}$ of variable composition. ${ }^{16}$ They are produced by reduction of aqueous $\mathrm{MoO}_{4}{ }^{2-}$, often under acidic conditions. By utilizing sophisticated synthesis methods, it is possible to get monodisperse and crystalline samples, for instance ring-shaped, supramolecular $\left\{\mathrm{Mo}_{154}\right\}$ clusters. ${ }^{16,17}$ Due to the partial reduction, i.e. the occurence of $\mathrm{d}^{1}$ centers at $\mathrm{Mo}^{\mathrm{V}}$ positions, $\mathrm{MB}$ shows a deep blue color. This strong color is often used to perform selective staining of samples for quantitative determination of reducing agents, ${ }^{18}$ silicates ${ }^{19}$ or phosphates. ${ }^{20}$ The formation of nanosized MB rings $(\mathrm{w} \approx 150$ ) was recently reported to occur via self-assembly of small linear precursor units $(w \approx 36) .{ }^{21} \mathrm{Up}$ to now, the formation of MB starting from neutral, molecular molybenum(VI) precursors has not been described. 


\section{MATERIALS AND METHODS}

Bis(acetylacetonato)dioxomolybdenum(VI) $\quad\left(\left[\mathrm{MoO}_{2}(\mathrm{acac}) 2\right]\right), \quad$ cyclohexanol $\quad(99 \%)$ and hydrogen peroxide $(30 \%)$ were purchased from Sigma-Aldrich and used as received. The reactions were carried out in a thermostated oil bath, equipped with immersion heater $(\Delta \mathrm{T}= \pm 1$ $\mathrm{K})$. In a typical run, the bath was heated to $85^{\circ} \mathrm{C}$, and a $3 \mathrm{~mL}$ glass vial was loaded with $40 \mathrm{mg}$ catalyst and $2 \mathrm{~mL}$ cyclohexanol, along with a magnetic stirring bar $(600 \mathrm{rpm})$. The reaction vessel was mounted such that the meniscus was below the surface of the oil bath. After a few minutes, the catalyst was completely dissolved. After 15 minutes conditioning, a portion of $100 \mu \mathrm{L} \mathrm{H}_{2} \mathrm{O}_{2}$ solution was added, which led to a bright yellow color. Within some minutes, the solution turned suddenly into a dark, turbid blue. Upon addition of another portion of $100 \mu \mathrm{L}$ $\mathrm{H}_{2} \mathrm{O}_{2}$ solution, the yellow, transparent liquid could be reestablished and after a sharp, welldefined induction time of about $8 \mathrm{~min}$, the blue color formation came back in an abrupt way. Like this, many cycles could be performed in series. The observed induction time was proportional to the amount of $\mathrm{H}_{2} \mathrm{O}_{2}$ added. In order to follow the color changes of the reaction, movies were shot using a Canon Powershot S5IS camera. The movies were colorimetrically analyzed on the computer, using a precision light sensor (Phidgets Inc., sensor 1127) as an external auxiliary. Transmittance was measured at $580 \mathrm{~nm}$. The induction time of the clock reaction was defined as the time between catalyst oxidation (i.e. time of $\mathrm{H}_{2} \mathrm{O}_{2}$ addition) and appearance of the first blue shimmer in the liquid. Dynamic laser scattering (DLS) was performed using a Malvern Mastersizer 2000, using isopropanol as dispersant, at a loading of $0.1 \mathrm{mg}$ MB per mL isopropanol. Gas chromatography was performed on a HP6890, equipped with flame ionization detector (FID) and mass spectrometer (MS). Product quantification was done on the FID with the RRF procedure described by Chaintreau and coworkers. ${ }^{22}$ Quantum 
chemical calculations were performed with the g03 set of programs, ${ }^{23}$ using the B3LYP functional. ${ }^{24}$ Geometry optimizations, frequency calculations and internal relaxed coordinate (IRC) scans were done on a generic basis set, consisting of $6-31 \mathrm{G}(\mathrm{d}, \mathrm{p})$ for $\mathrm{C} / \mathrm{H} / \mathrm{O}$ and LANL2DZ ${ }^{25}$ including an $\mathrm{f}$ polarization function for $\mathrm{Mo}^{26}$ Single-point calculations on the extended 6-311++G(df,pd) basis for $\mathrm{C} / \mathrm{H} / \mathrm{O}$ and the unchanged basis for Mo further refined the accuracy of the calculated reaction energies and adiabatic energy barriers. The relative energies of the stationary points were corrected for zero-point energy (ZPE) differences. Cartesian coordinates of the optimized transition states can be found in the Supporting Information. Kinetic modeling was done by numerical integration of the system of differential equations using MATLAB's ode45 solver.

\section{RESULTS AND DISCUSSION}

\section{Gradual MB formation in cyclohexanol}

We found that bis(acetylacetonato)dioxomolybdenum(VI), $\left.\left[\mathrm{Mo}^{\mathrm{VI}} \mathrm{O}_{2} \text { (acac) }\right)_{2}\right]$, a commercially available, yellow, organic-soluble molybdenum(VI) complex, is gradually converted to MB upon heating in cyclohexanol (Figure 1A), the latter acting both as solvent and reductant. This reaction is rather slow, putatively due to rather slow decoordination of the acac ligands. Similar to conventional $\mathrm{MB}$, i.e. obtained from reduction of $\mathrm{MoO}_{4}{ }^{2-}$, the solution was turbid, as a consequence of the high molecular aggregates. Figure 1B, obtained with DLS, shows that those aggregates are distributed around $0.1 \mu \mathrm{m}$ and are further agglomerated to $4 \mu \mathrm{m}$. This is similar to Muller's finding of primary $0.05 \mu \mathrm{m} \mathrm{MB}$ aggregates, ${ }^{27}$ along with the occurrence of large $1 \mu \mathrm{m}$ MB agglomerates in less polar medium..$^{28}$ 

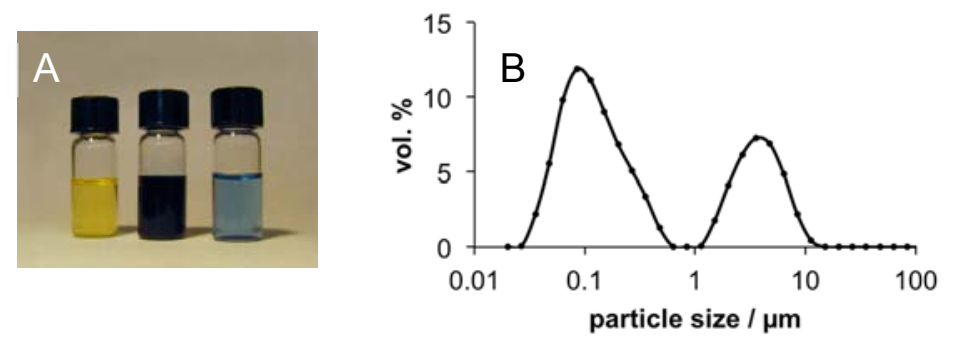

Figure 1. (A) Samples with molybdenum in oxidized state (yellow) and reduced state (dark blue, MB). The light blue sample is 100-fold diluted. (B) DLS size distribution of MB.

\section{Sudden MB formation: clock kinetics}

An interesting feature of the above-described, $\left[\mathrm{Mo}^{\mathrm{VI}} \mathrm{O}_{2}(\mathrm{acac})_{2}\right]$ based approach is that in the presence of $\mathrm{H}_{2} \mathrm{O}_{2}$, the formation of $\mathrm{MB}$ occurs in an abrupt way, and the concomitant color change is seen after a well-defined induction time (Figure 2). This is indicative of a reaction that follows clock kinetics.
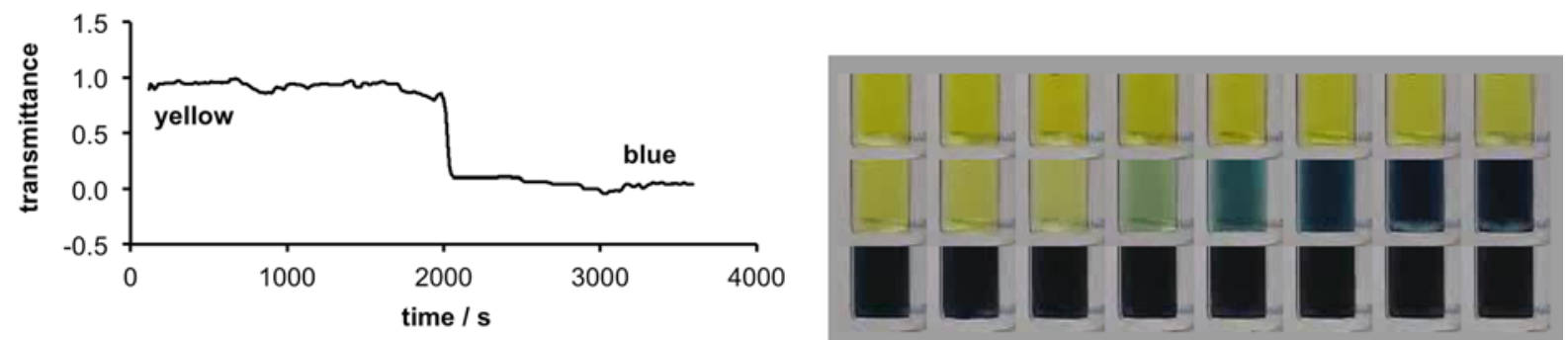

Figure 2. Left: Colorimetric tracking at $580 \mathrm{~nm}$ of the MB-based clock reaction. After the induction time, the system abruptly switches from yellow to blue. Solvent: cyclohexanol; [Mo]= $40 \mathrm{mM} ;\left[\mathrm{H}_{2} \mathrm{O}_{2}\right]_{0}=2 \mathrm{M} ; \mathrm{T}=85^{\circ} \mathrm{C}$. Right: Movie frames of the MB formation, $\mathrm{f}=0.1 \mathrm{~Hz}$. 
If - after the clock event has taken place - another portion of $\mathrm{H}_{2} \mathrm{O}_{2}$ is added, $\mathrm{MB}$ is reoxidized and the clock process can be reinitiated. Like this, multiple color switches can be provoked (Figure 3A). The observed induction time (tind) increases linearly as a function of the $\mathrm{H}_{2} \mathrm{O}_{2}$ amount added (Figure 3B). This lets us conclude that (i) complete $\mathrm{H}_{2} \mathrm{O}_{2}$ consumption is a prerequisite for the clock event to take place, i.e. $\left[\mathrm{H}_{2} \mathrm{O}_{2}\right]\left(t_{\text {ind }}\right)=0$, and (ii) the $\mathrm{H}_{2} \mathrm{O}_{2}$ consumption rate does not depend on $\left[\mathrm{H}_{2} \mathrm{O}_{2}\right]$. Thus, we assumed a simple rate law of first-order form (equation 1), which yields an expression for $t_{\text {ind }}$ (equation 2).

$$
\begin{aligned}
& -\mathrm{d}\left[\mathrm{H}_{2} \mathrm{O}_{2}\right] / \mathrm{d} t=k_{\text {clock }}[\mathrm{Mo}] \\
& t_{\text {ind }}=\left[\mathrm{H}_{2} \mathrm{O}_{2}\right]_{0} k_{\text {clock }^{-1}}[\mathrm{Mo}]^{-1}
\end{aligned}
$$

Indeed, by measuring $t_{\text {ind }}([\mathrm{Mo}])$ we observed that $k_{\text {clock }}$ was independent of [Mo] (Figure 3C), supporting the validity of our simple first-order rate law. Furthermore, an Arrhenius evaluation of $k_{\text {clock }}(\mathrm{T})$ in the temperature range of $65-95^{\circ} \mathrm{C}$ led an observed activation energy of $17 \pm 2 \mathrm{kcal} \mathrm{mol}^{-1}$ (Figure 3D).

The formation of MB was also observed with other primary and secondary alcohols, e.g. EtOH, $\mathrm{C}_{5} \mathrm{H}_{11} \mathrm{OH}, \mathrm{PhCH}_{2} \mathrm{OH}$, $i-\mathrm{PrOH}$, but not with tertiary alcohols, e.g. $t$ - $\mathrm{BuOH}$. For the primary alcohols, however, reoxidation cycles were not reproducible and the system was inactive after one cycle. The inertness of $t-\mathrm{BuOH}$ towards $\mathrm{MB}$ formation led to the conclusion that $\mathrm{C}=\mathrm{O}$ formation must be intimately connected with $\mathrm{Mo}^{\mathrm{VI}}$ reduction (reaction 3). This type of reactivity reminds of Trost's molybdenum-based alcohol oxidation system. ${ }^{29}$

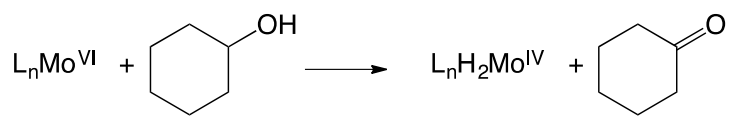



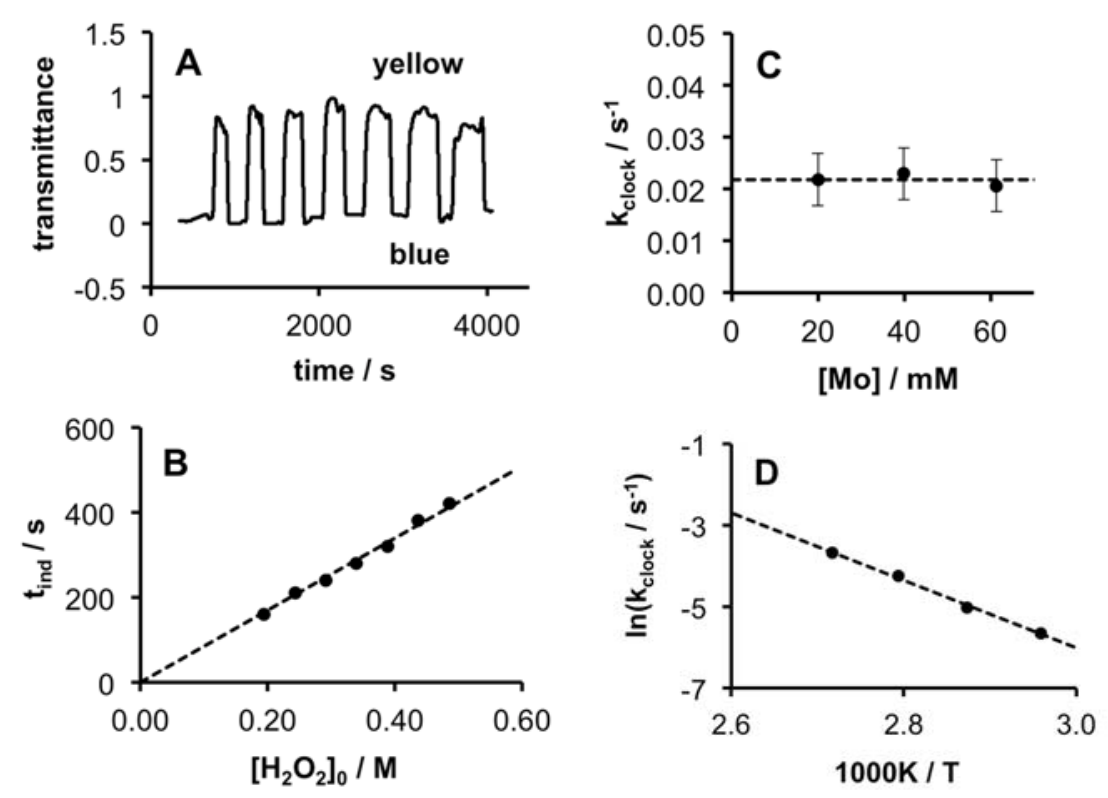

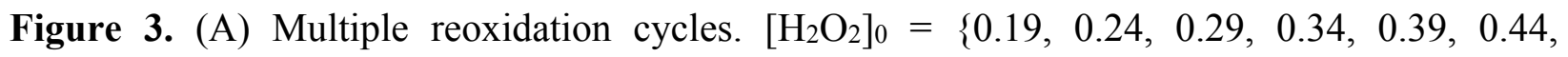
$0.49\} \mathrm{M} ;[\mathrm{Mo}]=40 \mathrm{mM} ; \mathrm{T}=85^{\circ} \mathrm{C}$. (B) Dependency of tind on $\left[\mathrm{H}_{2} \mathrm{O}_{2}\right]$, extracted from the transmittance vs. time plot in A. $[\mathrm{Mo}]=40 \mathrm{mM} ; 85^{\circ} \mathrm{C}$. (C) Concentration invariance of the firstorder rate constant $k_{c l o c k}\left(85^{\circ} \mathrm{C}\right)=0.02 \pm 0.01 \mathrm{~s}^{-1}$, as determined by equation 2 and linear regression of tind vs. $\left[\mathrm{H}_{2} \mathrm{O}_{2}\right]_{0}$ plots; $[\mathrm{Mo}]=\{20,40,60\} \mathrm{mM} ; T=85^{\circ} \mathrm{C}$. (D) Temperature dependency of $k_{\text {clock. }}[\mathrm{Mo}]=60 \mathrm{mM} ;\left[\mathrm{H}_{2} \mathrm{O}_{2}\right]_{0}=0.19 \mathrm{M} ; T=\{65,75,85,95\}^{\circ} \mathrm{C}$. The Arrhenius parameters are $E_{A}=17 \pm 2 \mathrm{kcal} \mathrm{mol}^{-1}$ and $\log \left(\mathrm{A} / \mathrm{s}^{-1}\right)=8.3 \pm 1$.

As a consequence, secondary alcohols work best for the clock reaction. We used cyclohexanol as the substrate of choice because of its low volatility and its high relevance as bulk chemical. As a matter of fact, catalytically increasing the ketone content in KA oils - by methods related to the presented one - could be an advantage in nylon- 6 monomer production. ${ }^{30}$ Note that keeping a good control over the ketone-to-alcohol ratio in this process is key, given its worldwide scale of $6 \times 10^{9} \mathrm{~kg} \mathrm{a}^{-1} \cdot 31$ 


\section{Mechanistic rationalization}

Based on the experimental observations above, on density functional theory (DFT) calculations and on literature knowledge about feasible and stable reaction intermediates, we propose a viable reaction mechanism, as given in Figure 4. The rational behind this mechanism is that a catalytic oxidation cycle - converting alcohol to ketone - gradually consumes $\mathrm{H}_{2} \mathrm{O}_{2}$ in the yellow phase of the reaction. As the clock event is reached, no more $\mathrm{H}_{2} \mathrm{O}_{2}$ is available to charge the catalyst. Yet, the alcohol oxidation goes on, now reducing the metal center instead of the peroxide, yielding $\mathrm{MB}$ with its typical blue color. By adding a second portion of $\mathrm{H}_{2} \mathrm{O}_{2}, \mathrm{MB}$ gets reoxidized and the cycle starts again.

The following paragraphs will describe the elementary reaction steps in the proposed mechanism. Under reaction conditions (i.e. oxidative conditions), the initial acetylacetonate ligands are known to get displaced by alcoholato ligands. ${ }^{32}$ The resting state of the catalyst is thus a tetrahedral bis(alcoholato)bis(oxo) species (1). In the presence of $\mathrm{H}_{2} \mathrm{O}_{2}$, an $\eta^{2}$-peroxo species (2) is formed. ${ }^{33,34}$ The peroxo ligand in $\mathbf{2}$ can unimolecularly oxidize a neighboring alcoholato ligand, yielding ketone and hydroxo complex 3. A final ligand exchange closes the catalytic cycle, in converting 3 back to $\mathbf{1}$. Overall, this catalytic cycle consumes $\mathrm{H}_{2} \mathrm{O}_{2}$ and alcohol, and produces ketone. The oxidation state of the molybdenum center is conserved throughout $\left(\mathrm{Mo}^{\mathrm{VI}}\right.$, i.e. $\mathrm{d}^{0}$, LMCT being responsible for the yellow color). Conclusively, Mo ${ }^{\mathrm{VI}}$ acts purely as a Lewis acid. 


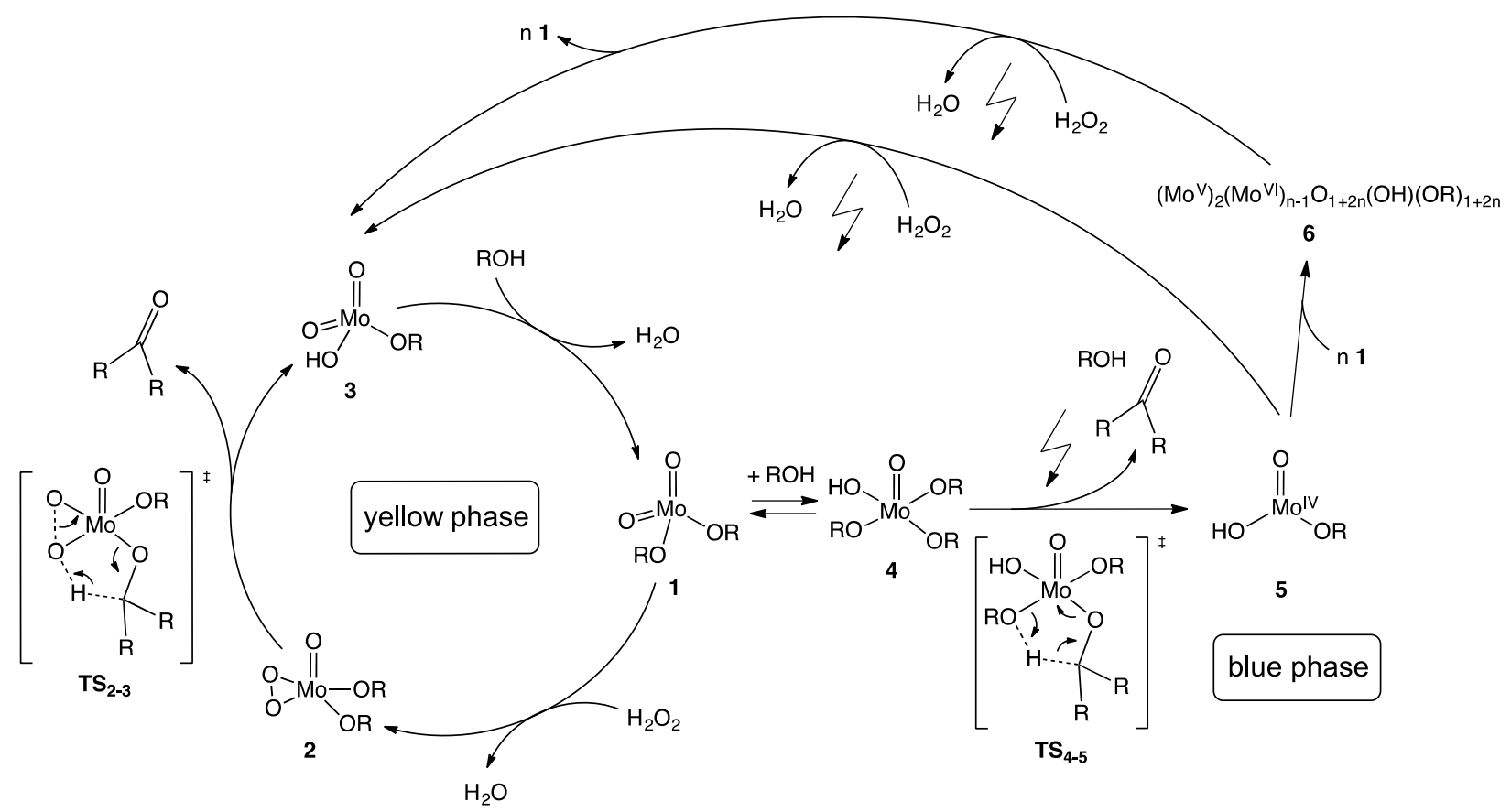

Figure 4. Proposed mechanism of the clock reaction. The redox ractions that introduce or remove d electrons onto or from the metal (indicated with thunderbolts) are responsible for the color changes between yellow $\left(\mathrm{Mo}^{\mathrm{VI}}, \mathbf{1 - 4}\right)$ and blue $\left(\mathrm{Mo}^{\mathrm{IV}}, \mathbf{5}\right.$ and $\left.\mathrm{Mo}^{\mathrm{V}}, \mathbf{6}\right)$. The reactions of the blue phase also occur in the yellow phase, albeit slower, and reactions $\mathbf{5} \rightarrow \mathbf{3}$ and $\mathbf{6} \rightarrow \mathbf{3}$ preclude accumulation of any $\mathbf{5}$ or $\mathbf{6}$ during the yellow phase.

After full consumption of $\mathrm{H}_{2} \mathrm{O}_{2}, 1$ can solvolytically add one alcoholato ligand (4) and then undergo self-oxidation to form ketone and a reduced $\mathrm{Mo}^{\mathrm{IV}}$ species (5). In this step, $\mathrm{Mo}^{\mathrm{VI}}$ takes over the role as oxidant. Similar to classical MB formation, the initially formed $\mathrm{Mo}^{\mathrm{IV}}$ species reacts with $n$ equivalents of $\mathbf{1}$, thereby undergoing comproportionation with one equivalent of $\mathbf{1}$ to form two $\mathrm{Mo}^{\mathrm{V}}$ centers, embedded in a $\mathrm{Mo}^{\mathrm{VI}}$ matrix (6). Based on earlier results, ${ }^{17}$ we assume a $\mathrm{Mo}^{\mathrm{VI}}: \mathrm{Mo}^{\mathrm{V}}$ ratio of $5: 1$, i.e. $n=11$. Finally, upon addition of another $\mathrm{H}_{2} \mathrm{O}_{2}$ portion, one can reoxidize $\mathbf{6}$ and release $n \mathbf{1}$ and 3. This brings the system back to the yellow phase catalytic cycle. 


\section{Input from quantum chemistry}

In the process of formulating the above reaction mechanism, we performed quantum chemical calculations using the B3LYP hybrid functional on an ample, generic basis set (see Materials and Methods). It is known from epoxidation chemistry that under oxidative conditions $\left[\mathrm{MoO}_{2}(\mathrm{acac})_{2}\right]$ loses its acetylacetonato ligands, those being replaced by alkoxo ligands. ${ }^{32}$ Thus, we based our calculations on computationally feasible, simplified $\left[\mathrm{MoO}_{2}(\mathrm{OMe})_{2}\right]$ models $\left(\mathrm{Me}=\mathrm{CH}_{3}\right)$, a method validated earlieron. ${ }^{13}$ Additionally, whenever $\alpha-\mathrm{H}$ atoms are being attacked, OiPr ligands $\left(i \operatorname{Pr}=\mathrm{CH}\left(\mathrm{CH}_{3}\right)_{2}\right)$ were taken as an accurate representation of the secondary alcohol cyclohexanol.

In the yellow phase, the decisive elementary reaction step is $\mathbf{2} \rightarrow \mathbf{3}$. Calculations describe the correspondent transition state $\left.\mathbf{(} \mathbf{T S}_{2-3}\right)$ as having a well-defined bicyclo[3.1.0] structure with planar core. This sigmatropic rearrangement allows the $\eta^{2}$-peroxo ligand to oxidize the alkoxo's $\alpha-\mathrm{H}$ atom. Thereby, ketone is produced and the $\mathrm{O}-\mathrm{O}$ bond undergoes reductive cleavage. The calculated structure is topologically very similar to the one reported for Sharpless-type hydroperoxide oxidation (Figure 5). ${ }^{13}$ Note that $\mathbf{T S}_{\mathbf{2 - 3}}$ is very likely also governing the Trost alcohol oxidation, ${ }^{29}$ rather than the recently proposed, ${ }^{35}$ but energetically disfavored ${ }^{36} \eta^{1}$ hydroperoxo TS. 

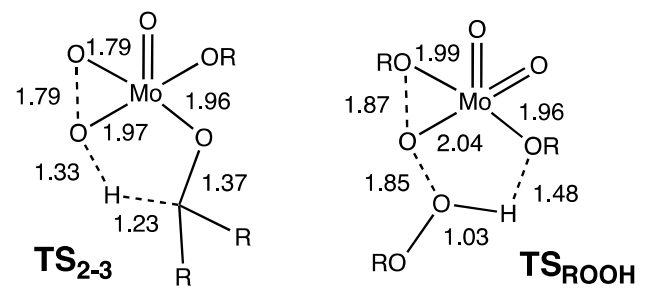

Figure 5. Comparison of calculated transition structures (B3LYP with generic basis set). Left: alcohol oxidation $\left(\mathbf{T S}_{\mathbf{2 - 3}}\right.$, this paper). Right: hydroperoxide oxidation $\left(\mathbf{T S}_{\mathbf{R O O H}}\right.$, adapted from reference 13). Numbers indicate bond lengths (in $\AA$ ) in the planar bicyclo[3.1.0] core.

Importantly, $\mathbf{T S}_{2-3}$ is heterolytic in nature and lies on the singlet hypersurface. Thus, it is purely based on the mild Lewis acidity of $\mathrm{Mo}^{\mathrm{VI}}$, activating and preorganizing both the oxidant and the substrate. Note that the crucial $\eta^{2}$-peroxo intermediate is a well-known structural motif in $\mathrm{Mo}^{\mathrm{VI}}$ based $\mathrm{H}_{2} \mathrm{O}_{2}$ activation, e.g. in the dark generation of singlet oxygen. ${ }^{34}$ Its formation from the dioxo precursor is favorable ${ }^{19}$ and cannot be rate-determining, since zero-order kinetics in $\left[\mathrm{H}_{2} \mathrm{O}_{2}\right]$ have been found (see above). An internal relaxed coordinate (IRC) scan confirmed the identity of $\mathbf{T S}_{2-3}$, in connecting $\mathbf{2}$ to $\mathbf{3}$ (Figure 6). The reaction is exothermic by $67 \mathrm{kcal} \mathrm{mol}^{-1}$, the calculated activation energy is $18.4 \mathrm{kcal} \mathrm{mol}^{-1}$ at $350 \mathrm{~K}$ (adiabatic energy barrier of $17.7 \mathrm{kcal} \mathrm{mol}^{-1}$ ), which is in good agreement with the experimentally found activation energy for the clock reaction $\left(17 \pm 2 \mathrm{kcal} \mathrm{mol}^{-1}\right.$, Figure 3D). 


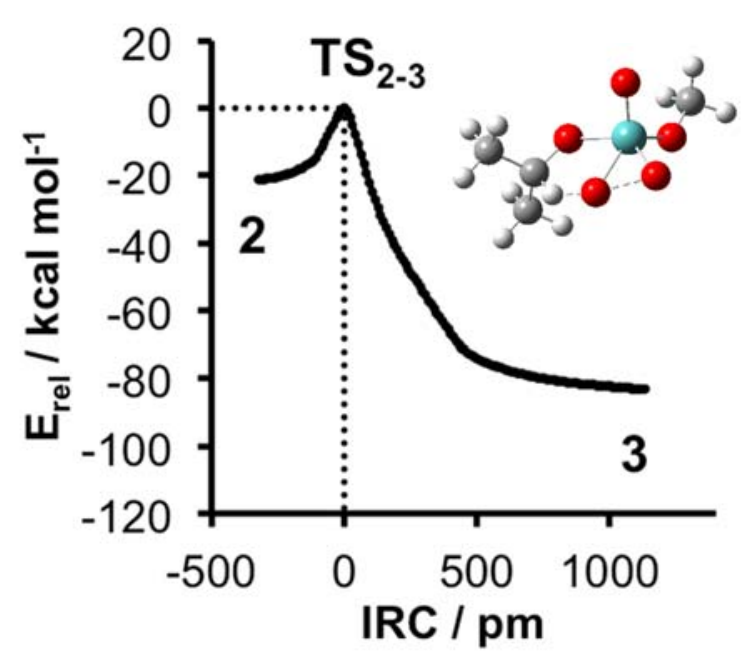

Figure 6. IRC scan of the alcohol oxidation step in the yellow phase (coupled to $\eta^{2}-\mathrm{O}_{2}$ reduction). Calculation based on $\mathrm{Mo}^{\mathrm{VI}}(\mathrm{O})\left(\eta^{2}-\mathrm{O}_{2}\right)(\mathrm{OMe})(\mathrm{OiPr}) .2$ lies at $-0.5 \mathrm{kcal}^{\mathrm{mol}}{ }^{-1}$ with respect to $\mathbf{1}$. Insert shows $\mathbf{T S}_{\mathbf{2}-3}$.

Once the clock event is reached, it is reaction $\mathbf{4} \rightarrow \mathbf{5}$ that brings about the color change to blue. The five-membered transition state $\mathbf{T S}_{4-5}$ corresponds to a sigmatropic [1,4]-hydrogen shift, equivalent to "half" of the bicyclo structures in $\mathbf{T S}_{2-3}$. Two electrons are reducing the metal center. The calculated activation energy is $28.1 \mathrm{kcal} \mathrm{mol}^{-1}$ at $350 \mathrm{~K}$ (adiabatic energy barrier of $27.4 \mathrm{kcal} \mathrm{mol}^{-1}$ ) (Figure 7). In principle, reduction can occur with or without solvolysis, as denoted by (i) and (ii), respectively, in Figure 8. Without solvolysis, however, the barrier increases to $49.4 \mathrm{kcal} \mathrm{mol}^{-1}$, overall, and reaction flux through this channel seems to be negligible. Although $\mathbf{T S}_{4-5}$ is closed shell, $\mathbf{5}$ has two near-degenerate spin states, i.e. singlet and triplet, lying at endothermicity levels of 19.2 and $20.1 \mathrm{kcal} \mathrm{mol}^{-1}$, respectively. We do not make any claim about the precise nature of the ground state of $\mathbf{5}$, and to some extent it is irrelevant anyway, since for the heavy element molybdenum, both spin states are quickly interchangeable, due to efficient spin-orbit coupling. ${ }^{37}$ 


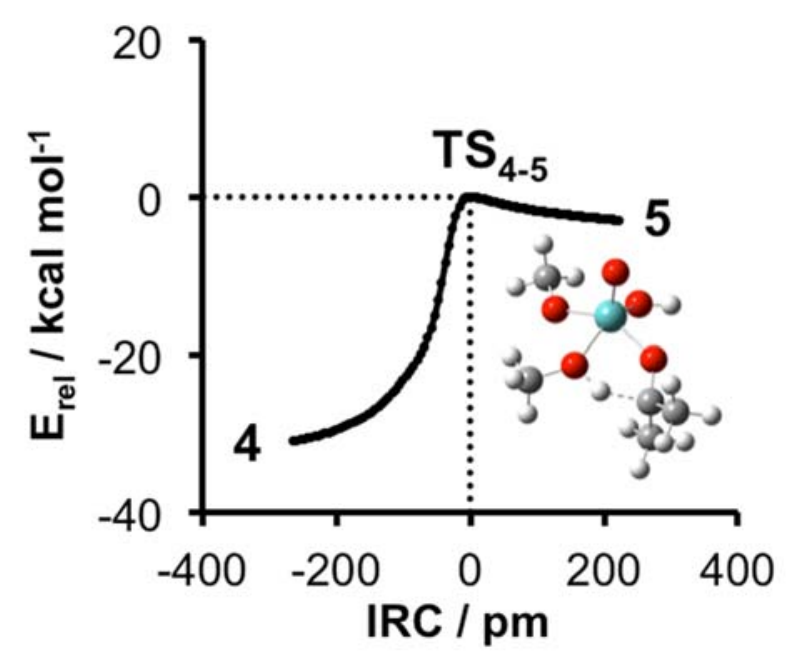

Figure 7. IRC scan of the alcohol oxidation step in the blue phase (reduction of $\mathrm{Mo}^{\mathrm{VI}}$ ). Calculation based on $\mathrm{Mo}^{\mathrm{VI}}(\mathrm{O})(\mathrm{OH})(\mathrm{OMe})_{2}(\mathrm{OiPr}) .4$ lies at $-0.1 \mathrm{kcal}^{-1} \mathrm{~mol}^{-1}$ with respect to 1 . Insert shows $\mathbf{T S}_{4-5}$.

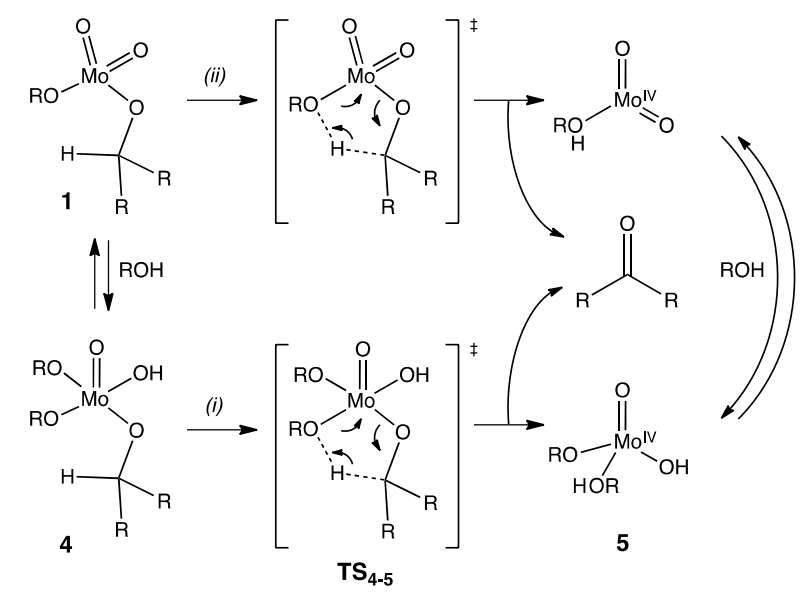

Figure 8. Catalyst reduction in the blue phase. Pathways with (i) and without (ii) solvolysis.

Concerning the fate of the $\mathrm{Mo}^{\mathrm{IV}}$ species (5), we find computational evidence for an energetically favorable comproportionation with $\mathrm{Mo}^{\mathrm{VI}}(\mathbf{1})$, as shown in reaction 4 . The calculated dimerization enthalpy amounts to -31 and $-33 \mathrm{kcal} \mathrm{mol}^{-1}$ for singlet and triplet spin states, 
respectively. Comparing this value to another case of $\mathrm{Mo}^{\mathrm{IV}} / \mathrm{Mo}^{\mathrm{VI}}$ comproportionation, where an experimental dimerization enthalpy of $-16 \mathrm{kcal} \mathrm{mol}^{-1}$ was found for a bis- $\kappa^{2} S$ based ligand field,$^{38}$ along with an activation energy for dimerization of only $7 \mathrm{kcal} \mathrm{mol}^{-1}$, the present case of dimerization can be assumed to be diffusion controlled, since the higher dimer stability $\left(\Delta \Delta \mathrm{H}_{(2)}\right)$ exceeds the bis- $\kappa^{2} S$ activation energy by more than a factor of two.

$$
\begin{aligned}
& \mathrm{Mo}^{\mathrm{IV}}(\mathbf{5})+\mathrm{Mo}^{\mathrm{VI}}(\mathbf{1}) \rightarrow\left(\mathrm{Mo}^{\mathrm{V}}\right)_{2} \\
& \left(\mathrm{Mo}^{\mathrm{V}}\right)_{2}+(n-1) \mathbf{1} \rightarrow \mathbf{6}
\end{aligned}
$$

Mulliken atomic charge analysis of the dimer reveals clearly the comproportionation having occurred (Figure 9). This is corroborated by the absence of Jahn-Teller distortion and a spin density (in triplet state) of about unity for both molybdenum centers. After dimerization, further molybdenum units will add, until the final form of $\mathrm{MB}$ is reached (reaction 5, with an estimated $n=11$, see above).

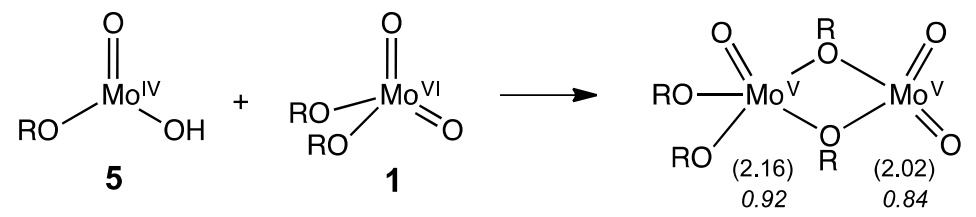

Figure 9. Comproportionation/dimerization of $\mathrm{Mo}^{\mathrm{IV}}(\mathbf{5})$ with $\mathrm{Mo}^{\mathrm{VI}}(\mathbf{1})$. The bracketed and italic numbers indicate Mulliken charge and spin density, respectively (atomic units). 


\section{Kinetic modeling}

In order to verify the ability of the presented mechanism to explain the experimentally observed clock behavior, we set up a full kinetic model (Table 1). Indeed, by numerically solving this system of differential equations (see Materials and Methods), we could qualitatively reproduce the abrupt color change (Figure 10). This is a valuable piece of evidence in favor of the presented mechanism. Note that although some clock reactions involve autocatalysis, ${ }^{4}$ this was not found to be necessary in the current case: Our model is able to explain the clock behavior in the absence of autocatalysis, in particular due to reactions $6 \rightarrow \mathbf{3}$ and $\mathbf{5} \rightarrow \mathbf{3}$. These reactions destroy any formed MB by reaction with $\mathrm{H}_{2} \mathrm{O}_{2}$. When $\mathrm{H}_{2} \mathrm{O}_{2}$ is exhausted, any formed MB cannot be destroyed and the color appears. In the (hypothetical) absence of these reactions, MB would form slowly but in a defined speed and the color should appear gradually.

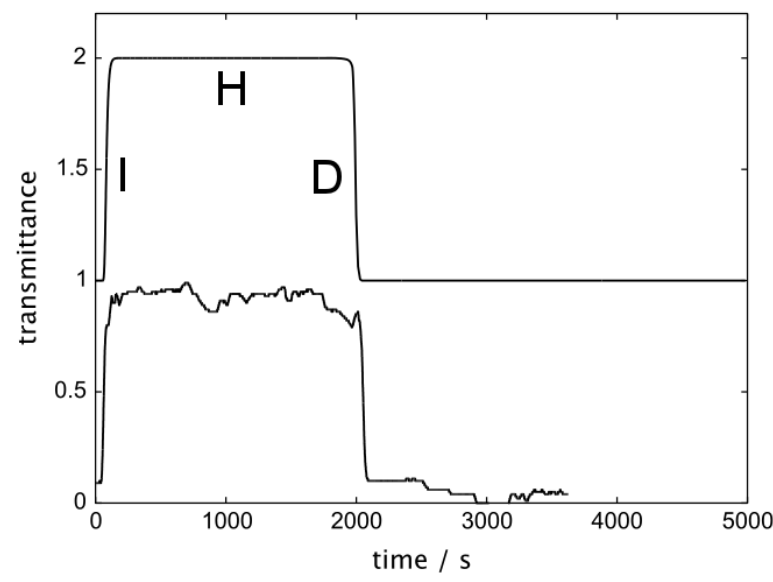

Figure 10. Comparison of experimental data with kinetic model (translated by 1.0 in y direction for clarity). The characteristic time domains of the reaction are labeled I (increase), $\mathrm{H}$ (high) and $\mathrm{D}$ (decrease). $[\mathrm{Mo}]=60 \mathrm{mM} ;\left[\mathrm{H}_{2} \mathrm{O}_{2}\right] 0=2 \mathrm{M} ; \mathrm{T}=85^{\circ} \mathrm{C}$. 
Moreover, the kinetic modeling provided approximate rate constants of some elementary reaction steps involved (Table 1). In fact, tind is the main but not the only relevant parameter in this system. Rather, the rates of MB formation and MB oxidation do influence the experimental data (abruptness) in the D and I domains, respectively (Figure 10). The model rate constants were subject to a sensitivity analysis (multiplication and division by a factor of two, visually checking whether the curve deviated from its original shape and if yes which of the three domains was affected). It was found that the above-mentioned three rate constants were sensitive in their respective domains. Moreover, the kinetic model breaks down if $k_{1-2}$ or $k_{5-3}$ are set at too low levels. In conclusion, the model provides estimated values for three rate constants $\left(k_{2-3}, k_{4-5}\right.$ and $\left.k_{6-3}\right)$ as well as estimated minimum values for two more rate constants $\left(k_{1-2}\right.$ and $\left.k_{5-3}\right)$. Note that for a more reliable determination of the individual rate constants, further spectroscopic studies on isolated intermediates or on single-step elementary reactions should be performed. For our kinetic modeling, in order to have clearly distinct domains, we used a high $\mathrm{H}_{2} \mathrm{O}_{2}$ concentration (Figure 10). Yet, when the model was reevaluated at low $\mathrm{H}_{2} \mathrm{O}_{2}$ concentrations, the abrupt color changes could only be achieved when the apparent value of $k_{6-3}$ was increased accordingly, suggesting that the true rate law for $\mathbf{6} \rightarrow \mathbf{3}$ is more complex than assumed in our simple model (and thus $k_{6-3}$ not being a true physical quantity), a fact again asking for more indepth spectroscopic studies. The complication with the rate law for $\mathbf{6} \rightarrow \mathbf{3}$ is understandable, since 6 is a cluster and its disintegration cannot be an elementary reaction step. In principle, the same holds for $\mathbf{5} \rightarrow \mathbf{6}$, but due to the very fast dimerization (see above) the associated rate constant was found to be insensitive anyway.

Note that although there is no strict, analytical relation between the phenomenological quantity $k_{c l o c k}$ and the individual rate constants from the model, it is approximately true that $k_{c l o c k} \approx k_{2-3}$ 
(see Figure 3C and Table 1). This can be rationalized, as on one hand, the timing of the clock event coincides with the moment of $\mathrm{H}_{2} \mathrm{O}_{2}$ exhaustion, and on the other hand, the proposed $\mathrm{H}_{2} \mathrm{O}_{2}$ depletion mechanism (Figure 4) has its rate-determining step in the unimolecular reaction step $\mathbf{2} \rightarrow \mathbf{3}$. The value of $k_{\text {clock }}$ is not strongly influenced by the rate constants of the other elementary reaction steps. However, the magnitudes of those other rate constants are a necessary prerequisite for the clock phenomenon as such to occur at all. For instance, if $k_{6-3}$ would be too slow, some MB might accumulate during the yellow phase and a steady, gradual color change would be observed.

Table 1. Kinetic model of the proposed mechanism. Rate constants are at $85^{\circ} \mathrm{C}$.

\begin{tabular}{|c|c|c|c|c|}
\hline \multicolumn{2}{|c|}{ reaction } & rate law & $\mathbf{k}_{\text {model }}$ & sensitive (domain) \\
\hline \multirow{4}{*}{$\frac{3}{\frac{3}{0}}$} & $1 \rightarrow 2$ & $k_{1-2}[\mathbf{1}]\left[\mathrm{H}_{2} \mathrm{O}_{2}\right]$ & $5 \times 10^{2} \mathrm{M}^{-1} \mathrm{~s}^{-1}$ & only if lowered $(\mathrm{H})$ \\
\hline & $2 \rightarrow 3$ & $k_{2-3}[2]$ & $1.5 \times 10^{-2} \mathrm{~s}^{-1 \mathrm{~b}}$ & yes $(\mathrm{H})$ \\
\hline & $3 \rightarrow 1$ & $k_{3-1}[3][\mathrm{ROH}]$ & fast $^{c}$ & no \\
\hline & $1 \rightarrow 4$ & \multirow{2}{*}{$k_{4-5}\left(K_{\left.1-4^{-1}+1\right)^{-1}[\mathbf{1}]}\right.$} & \multirow{2}{*}{$4 \times 10^{-4} \mathrm{~s}^{-1 \mathrm{~d}}$} & \multirow{2}{*}{ yes (D) } \\
\hline \multirow{4}{*}{$\stackrel{\stackrel{0}{ٍ}}{0}$} & $4 \longrightarrow 5$ & & & \\
\hline & $5 \rightarrow 6$ & $k_{5-6}[\mathbf{5}][\mathbf{1}]$ & $10^{3} \mathrm{M}^{-1} \mathrm{~s}^{-1 \mathrm{e}}$ & no \\
\hline & $5 \rightarrow 3$ & $k_{5-3}[\mathbf{5}]\left[\mathrm{H}_{2} \mathrm{O}_{2}\right]$ & $1 \mathrm{M}^{-1} \mathrm{~s}^{-1 \mathrm{f}}$ & only if lowered (D) \\
\hline & $6 \rightarrow 3$ & $k_{6-3}[\mathbf{6}]\left[\mathrm{H}_{2} \mathrm{O}_{2}\right]$ & $5 \times 10^{-2} \mathrm{M}^{-1} \mathrm{~s}^{-1}$ & yes (I) \\
\hline
\end{tabular}

${ }^{a}$ Refers to the domains defined in Figure 10.

${ }^{\mathrm{b}}$ The agreement between $E_{A}\left(k_{2-3}\right) \exp$ and $E_{A}\left(k_{2}-3\right)$ calc was already discussed above. (k2-3)model agrees with $k_{\text {clock }}$ in Figure $3 \mathrm{C}$. The corrected, recommended value for $k_{2-3}$ is $1.1 \times 10^{-2} \mathrm{~s}^{-1}$, see chapter 'side-reactivity'.

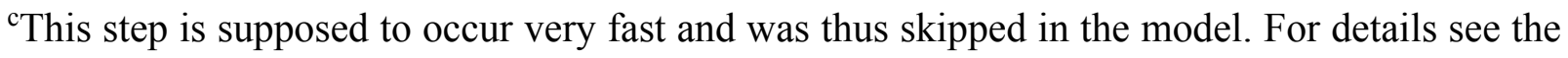
Supp. Inf.

${ }^{\mathrm{d}}$ Refers to $k_{4-5}$, not $k_{1-4}$. Dividing $k_{4-5}$ by the literature prefactor for five-membered hydrogen shifts, i.e. $6 \times 10^{12} \mathrm{~s}^{-1}$ including six-fold degeneracy, ${ }^{39}$ we get $E_{A}\left(k_{4-5}\right)_{\text {model }}=26.5 \mathrm{kcal} \mathrm{mol}^{-1}$, in 
reasonable agreement with our calculations, i.e. $E_{A}\left(k_{4-5}\right)_{\text {calc }}=28.1 \mathrm{kcal} \mathrm{mol}^{-1}$. Also, we assume $K_{1-4} \approx 1$, see derivations in the Supp. Inf.

${ }^{e}$ Conservative estimate. After comparison with the bis- $\kappa^{2} S$ case (see above), $k_{5-6}$ is probably diffusion controlled. The value refers to the initial dimerization step in the $\mathbf{5} \rightarrow \mathbf{6}$ sequence.

f Based on the dilution of reduced species in $6(n=11$, see text $)$ and the potential steric hindrance in accessing those sites.

From the model, interesting information about the concentration changes during the reaction can be obtained (Figure 11). For instance, during the yellow phase, peroxo species 2 clearly dominates. At the clock event, which is the moment of $\mathrm{H}_{2} \mathrm{O}_{2}$ exhaustion, a sudden transient buildup of 1 and 4 can be observed. The availability of 4 gives room for formation of MB. Interestingly, $\mathbf{5}$ does not accumulate to any reasonable degree, but gets immediately transferred to 6. This is caused by the fast comproportionation (even with the conservative $k_{5-6}$ value chosen). Although the quantitative transfer of $\mathbf{4}$ to $\mathbf{6}$ does need some time, an abrupt color change is observed at the clock event, since the molar absorption coefficient of $\mathbf{6}$ is very high, i.e. $\varepsilon=$ $5000 \mathrm{M}^{-1} \mathrm{~cm}^{-1}$ per $\mathrm{Mo}^{\mathrm{V}}$ center. ${ }^{40}$ By acknowledging the linear time dependency of $\left[\mathrm{H}_{2} \mathrm{O}_{2}\right]$ (Figure 10 right), the experimentally observed zeroth order with respect to $\left[\mathrm{H}_{2} \mathrm{O}_{2}\right]$ is correctly reproduced by the model. Moreover, another set of modeling results also confirmed first order behavior with respect to the catalyst (Figure 12). 

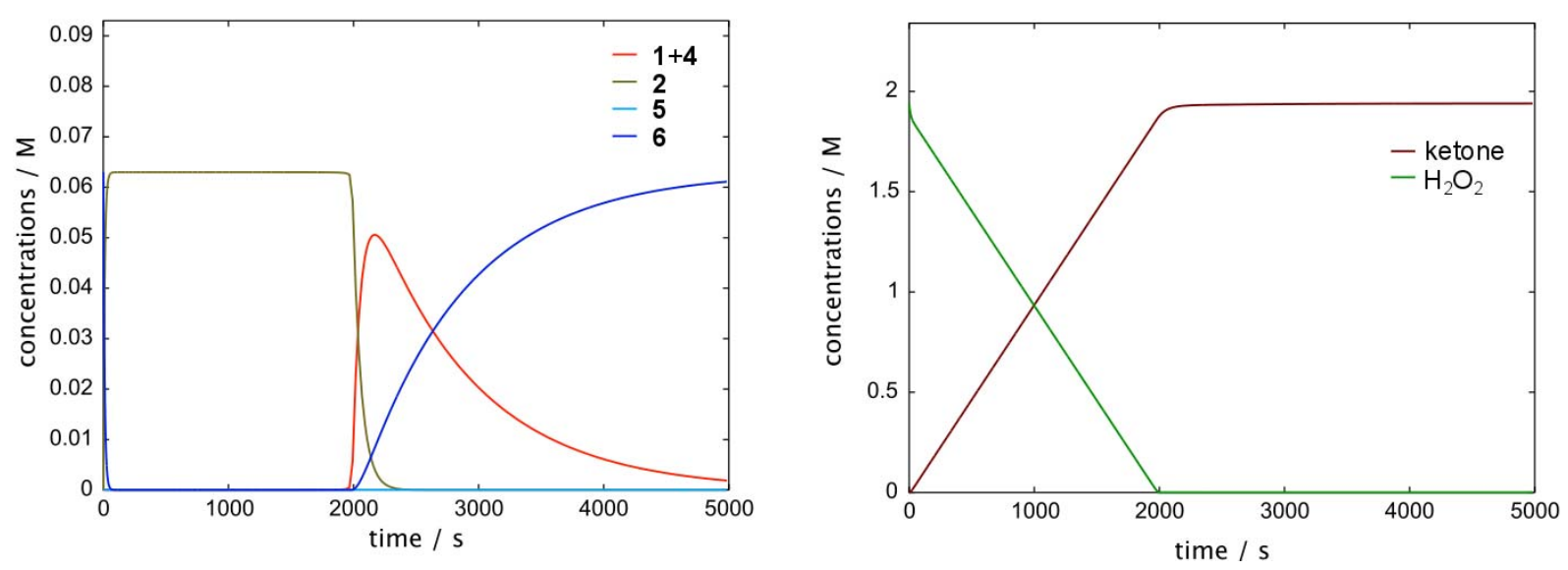

Figure 11. Left: Catalyst speciation curves, as obtained from the modeling results. As we assume the reaction $\mathbf{3} \rightarrow \mathbf{1}$ to be very fast (see Table 1), it is [3] $=0$. Right: Concentration changes of the stoichiometric species. $[\mathrm{Mo}]=60 \mathrm{mM} ;\left[\mathrm{H}_{2} \mathrm{O}_{2}\right]_{0}=2 \mathrm{M} ; T=85^{\circ} \mathrm{C}$.

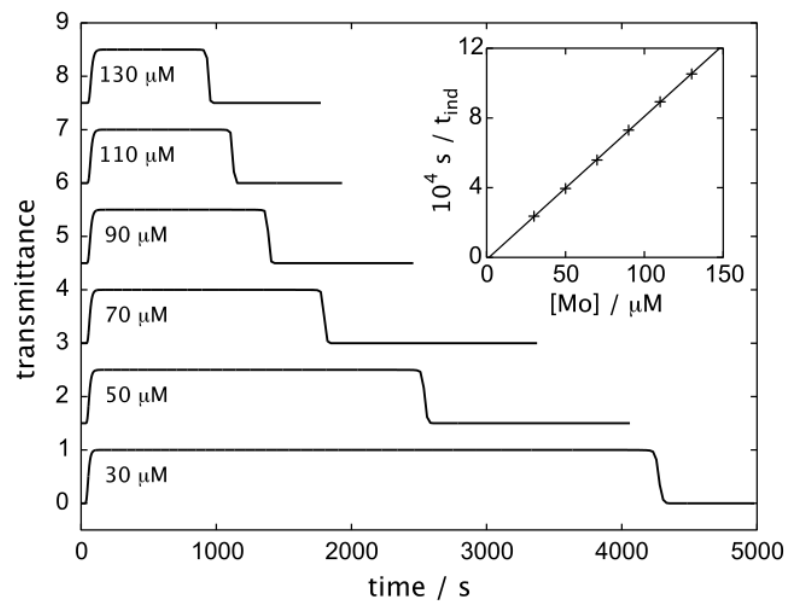

Figure 12. Modeling results for various catalyst concentrations. [Mo] as indicated; $\left[\mathrm{H}_{2} \mathrm{O}_{2}\right]_{0}=2$ $\mathrm{M} ; T=85^{\circ} \mathrm{C}$. Each curve translated by 1.5 in y-direction for clarity. The insert plot shows that the model predicts $1 /$ tind to be proportional to [Mo]. This confirms first-order kinetics (see equation 1). 


\section{Radical side-reactivity}

In order to explore the feasibility of applying the title reaction to catalytic applications, we monitored the formation of ketone (stemming from the contributions of reactions $\mathbf{2} \rightarrow \mathbf{3}$ and $\mathbf{4} \rightarrow \mathbf{5}$ ) with gas chromatography. The cyclohexanone peak was identified by GC-MS and quantified by GC-FID. Under our conditions, we found an overall efficiency in converting cyclohexanol to cyclohexanone of roughly $70 \%$, with respect to $\mathrm{H}_{2} \mathrm{O}_{2}$ (Figure 13). Likely, there is room for significant optimization of this value, e.g. by using continuous addition protocols. We ascribe the partial loss of $\mathrm{H}_{2} \mathrm{O}_{2}$ to catalytic disproportionation. This hypothesis is supported by the observation of some gas bubbles during the yellow phase, which are characteristic of Fenton-like $\mathrm{H}_{2} \mathrm{O}_{2}$ disproportionation processes. ${ }^{41}$ The immediate consequence of this finding is that the recommended value of the rate constant $k_{2-3}\left(\mathbf{2} \rightarrow \mathbf{3}\right.$ is the main $\mathrm{H}_{2} \mathrm{O}_{2}$ sink) should be the value derived from kinetic modeling, corrected by a factor of 0.7 , i.e. $0.011 \mathrm{~s}^{-1}$ instead of $0.015 \mathrm{~s}^{-1}$ (Table 1).

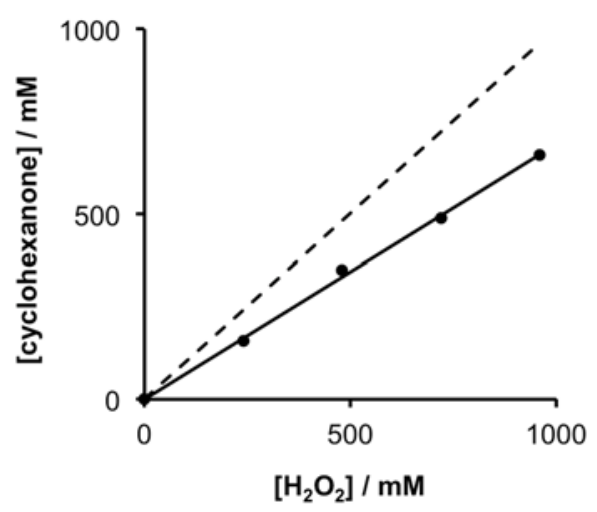

Figure 13. Observed increase in cyclohexanone concentration. The dots represent four consecutive clock cycles, each run at $\left[\mathrm{H}_{2} \mathrm{O}_{2}\right]_{0}=0.24 \mathrm{M}$. $[\mathrm{Mo}]=40 \mathrm{mM} ; T=85^{\circ} \mathrm{C}$. The dashed parity line indicates full yield, the plain trendline has a slope of 0.7 . 
Note that for a more rigorous treatment of those radical side-processes - by inclusion into the kinetic model - an unjustifiable amount of additional equations would enter the simulation, ${ }^{42}$ obscuring the central findings of this paper. As to the mechanism of disproportionation, it stands to reason that the same molybdenum peroxo species that is responsible for alcohol oxidation (i.e. 2) is also responsible for $\mathrm{H}_{2} \mathrm{O}_{2}$ destruction. Indeed, following the bicyclo[3.1.0] topology of the $\mathrm{Mo}^{\mathrm{VI}}$-peroxo catalyzed ROOH oxidation transition state in Figure 5 ( $\mathbf{T S}_{\mathbf{R O O H}}$ ), we were able to localize a completely analogous $\mathrm{H}_{2} \mathrm{O}_{2}$ oxidation transition state ( $\mathbf{T S}_{2-7}$ in Figure 14A). As before, a rigorous IRC analysis was performed to confirm the identity of this transition state (Figure 15). The found reactivity parallel between the symmetric $\eta^{2}$-peroxido species $\mathbf{2}$ and the asymmetric $\eta^{1}$-hydroperoxido species preceding $\mathbf{T} \mathbf{S}_{\mathbf{R O O H}}$ was recently predicted by Amini and coworkers. ${ }^{43}$

A

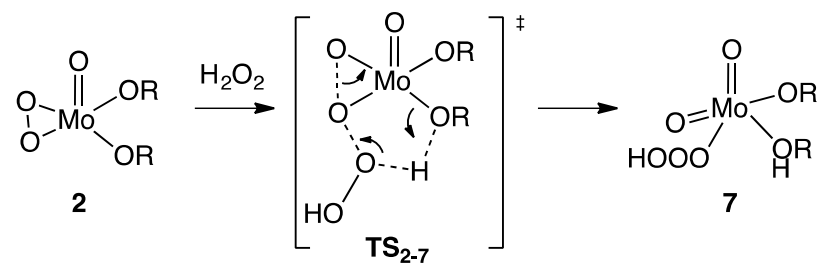

B

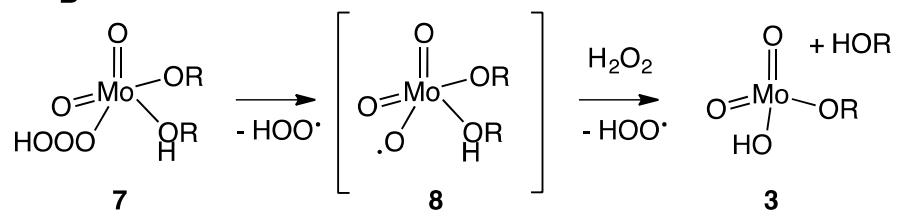

Figure 14. (A) Heterolytic activation of $\mathrm{H}_{2} \mathrm{O}_{2}\left(E_{A}\left(k_{2-7}\right)=20.9 \mathrm{kcal} \mathrm{mol}^{-1} ; \Delta H_{2-7}=-14 \mathrm{kcal} \mathrm{mol}^{-}\right.$ ${ }^{1}$ ), leading to $\mathrm{Mo}^{\mathrm{VI}}$ trioxide 7. (B) 7 forms radicals upon homolytic $\mathrm{O}-\mathrm{O}$ scission and subsequent $\mathrm{H}$ abstraction from $\mathrm{H}_{2} \mathrm{O}_{2} . \Delta H_{7-8}$ and $\Delta H_{8-3}$ are 19 and $-22 \mathrm{kcal} \mathrm{mol}^{-1}$, respectively. 


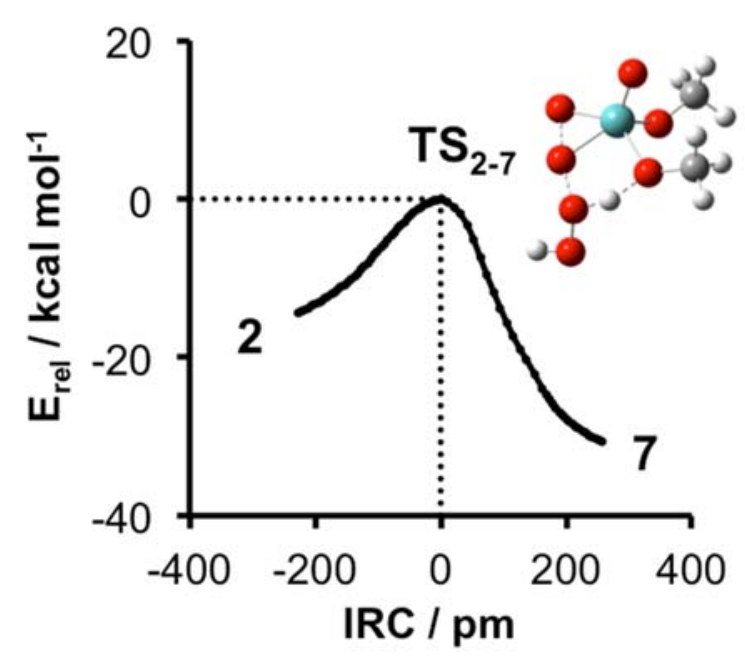

Figure 15. IRC scan of the for side-reaction $\mathbf{2} \rightarrow \mathbf{7}$ (oxidation of $\mathrm{H}_{2} \mathrm{O}_{2}$ ). Calculation based on $\mathrm{Mo}^{\mathrm{VI}}(\mathrm{O})\left(\mathrm{O}_{2}\right)(\mathrm{OMe})_{2} .2$ lies at $-0.5 \mathrm{kcal} \mathrm{mol}^{-1}$ with respect to $\mathbf{1}$. Insert shows $\mathbf{T S}_{2-7}$.

It has been shown that $\mathbf{T S}_{\mathbf{R O O H}}$ (Figure 5) is followed by homolysis of the intermediately formed, labile molybdenum trioxide unit; ${ }^{13}$ a conclusion which is equally valid for species $7 .{ }^{44}$ This homolysis, taking place on a $\tau_{7-8}<1 \mathrm{~ms}$ timescale, ${ }^{45}$ leads to the formation of an HOO radical and a complex radical 8, which reacts with $\mathrm{H}_{2} \mathrm{O}_{2}$ in a diffusion-controlled way $(\tau 8-3<$ $1 \mu \mathrm{s})^{46}$ to yield 3 and another $\mathrm{HOO}^{\circ}$ radical (Figure 14B). Finally, it is well known that HOO${ }^{\circ}$ radicals readily terminate in a head-to-tail fashion on the triplet hypersurface (bimolecular rate constant $2 \times 10^{9} \mathrm{M}^{-1} \mathrm{~s}^{-1}$ ), yielding $\mathrm{H}_{2} \mathrm{O}_{2}$ and ${ }^{3} \mathrm{O}_{2} \cdot{ }^{47}$ As to the electronic configuration of $\mathbf{8}$, both Mulliken population and bond length analyses revealed a structure that is best described by a localized oxyl radical rather than a mesomerically diffuse form (see Supp. Inf.).

\section{CONCLUSION}

In summary, we report a clock reaction based on sudden $\mathrm{Mo}^{\mathrm{VI}}$ reduction to molybdenum blue in the presence of alcohol and hydrogen peroxide. A sharp color switch from yellow to blue 
occurs after a well-defined induction time. The peculiar clock kinetics were explored experimentally and rationalized by a DFT-derived reaction mechanism. The ability of the proposed mechanism to reproduce the experimental findings was confirmed by explicit kinetic modeling. Moreover, the modeled rate constants of elementary reaction steps were benchmarked with theoretical predictions, where possible. A minor side-reaction was found to trigger some hydrogen peroxide disproportionation. Potential application of the title reaction to catalytic alcohol oxidation processes as well as conclusions for molybdenum-catalyzed alcohol oxidations in general were discussed.

\section{ASSOCIATED CONTENT}

Supporting Information. Cartesian coordinates of optimized intermediates and transition states. This material is available free of charge via the Internet at http://pubs.acs.org.

\section{AUTHOR INFORMATION}

Corresponding Author

*Email: kfjensen@mit.edu

\section{ACKNOWLEDGMENTS}

UN thanks the Swiss National Science Foundation for support. 


\section{REFERENCES}

(1) Lente, G.; Bazsa, G.; Fabian, I. What is and what isn't a clock reaction? New J. Chem. 2007, 31, 1707-1707.

(2) Landolt, H. Ueber die Zeitdauer der Reaction zwischen Jodsäure und schwefliger Säure. Ber. Dtsch. Chem. Ges. 1886, 19, 1317-1365.

(3) Church, J. A.; Dreskin, S. A. Kinetics of Color Development in the Landolt ("iodine clock") Reaction. J. Phys. Chem. 1968, 72, 1387-1390.

(4) Oliveira A. P.; Faria, R. B. The chlorate-iodine clock reaction. J. Am. Chem. Soc. 2005, 127, 18022-18023.

(5) Kimmerle, B.; Baiker, A.; Grunwaldt, J.-D. Oscillatory behaviour of catalytic properties, structure and temperature during the catalytic partial oxidation of methane on $\mathrm{Pd} / \mathrm{Al}_{2} \mathrm{O}_{3}$. Phys. Chem. Chem. Phys. 2010, 12, 2288-2291.

(6) Girard, C.; Kagan, H. B. Nonlinear effects in asymmetric synthesis and stereoselective reactions: ten years of investigation. Angew. Chem. Int. Ed. 1998, 37, 2922-2959.

(7) Lengyel, I.; Li, J.; Epstein, I. R. Systematic design of chemical oscillators. 82. Dynamical study of the chlorine dioxide-iodide open system oscillator. J. Phys. Chem. 1992, 96, 7032-7037.

(8) (a) Steinbock, O.; Hamik, C. T.; Steinbock, B. Oxygen inhibition of oscillations in the Belousov-Zhabotinsky reaction. J. Phys. Chem. A 2000, 104, 6411-6415. (b) Berenstein, I.; Beta, C. Spatiotemporal chaos arising from standing waves in a reaction-diffusion system with cross-diffusion. J. Chem. Phys. 2012, 136, 034903. (c) Wang, J.; Sorensen, P. G.; Hynne, F. Transient complex oscillations in the closed Belousov-Zhabotinsky reaction: experimental and 
computational studies. Zeitsch. Phys. Chem. 1995, 192, 63-76. (d) Kawczynski, A. L.; Comstock, W. S.; Field, R. J. The evolution of patterns in a homogeneously oscillating medium. Physica D: Nonlin. Phen. 1992, 54, 220-234.

(9) (a) Bray, W. C.; Liebhafsky, H. A. Reactions involving hydrogen peroxide, iodine and iodate ion. I. Introduction. J. Am. Chem. Soc. 1931, 53, 38-44. (b) Schmitz, G. Iodine oxidation by hydrogen peroxide in acidic solutions, Bray-Liebhafsky reaction and other related reactions. Phys. Chem. Chem. Phys. 2010, 12, 6605-6615. (c) Schmitz, G.; Furrow, S. Kinetics of the iodate reduction by hydrogen peroxide and relation with the Briggs-Rauscher and BrayLiebhafsky oscillating reactions. Phys. Chem. Chem. Phys. 2012, 14, 5711-5715. (d) Olexova, A.; Mrakavova, M.; Melichercik, M.; Treindl, L. Oscillatory System $\mathrm{I}^{-}, \mathrm{H}_{2} \mathrm{O}_{2}, \mathrm{HClO}_{4}$ : The Modified Form of the Bray-Liebhafsky Reaction. J. Phys. Chem. A 2010, 114, 7026-7029.

(10) (a) Briggs, T. S.; Rauscher, W. C. An oscillating iodine clock. J. Chem. Educ. 1973, 50, 496-496. (b) De Kepper, P.; Epstein, I. R. Mechanistic study of oscillations and bistability in the Briggs-Rauscher reaction. J. Am. Chem. Soc. 1982, 104, 49-55. (c) Muntean, N.; Szabo, G.; Wittmann, M.; Lawson, T.; Fulop, J.; Noszticzius, Z.; Onel, L. Reaction Routes Leading to $\mathrm{CO}_{2}$ and $\mathrm{CO}$ in the Briggs-Rauscher Oscillator: Analogies between the Oscillatory BR and BZ Reactions. J. Phys. Chem. A 2009, 113, 9102-9108. (d) Cervellati, R.; Greco, E.; Furrow, S. D. Experimental and Mechanistic Investigation of an Iodomalonic Acid-Based Briggs-Rauscher Oscillator and its Perturbations by Resorcinol. J. Phys. Chem. A 2010, 114, 12888-12892.

(11) (a) Chong, A. O.; Sharpless, K. B. Mechanism of the molybdenum and vanadium catalyzed epoxidation of olefins by alkyl hydroperoxides. J. Org. Chem. 1977, 42, 1587-1590. (b) Sharpless, K. B.; Michaelson, R. C. High stereo-and regioselectivities in the transition metal 
catalyzed epoxidations of olefinic alcohols by tert-butyl hydroperoxide. J. Am. Chem. Soc. 1973, 95, 6136-6137. (c) Topuzova, M. G.; Kotov, S. V.; Kolev, T. M. Epoxidation of alkenes in the presence of molybdenum-squarate complexes as novel catalysts. Appl. Cat. A 2005, 281, $157-$ 166.

(12) Sheldon, R. A. Molybdenum $\square$ catalysed epoxidation of olefins with alkyl hydroperoxides I. Kinetic and product studies. Recl. Trav. Chim. Pays-Bas 1973, 92, 253-266.

(13) Neuenschwander, U.; Meier, E.; Hermans, I. Catalytic Epoxidations with Peroxides: Molybdenum Trioxide Species as the Origin of Allylic Byproducts. Chem. Eur. J. 2012, 18, 6776-6780.

(14) Lane, B. S.; Burgess, K. Metal-catalyzed epoxidations of alkenes with hydrogen peroxide. Chem. Rev. 2003, 103, 2457-2473.

(15) Jimtaisong, A.; Luck, R. L. Synthesis and Catalytic Epoxidation Activity with TBHP and $\mathrm{H}_{2} \mathrm{O}_{2}$ of Dioxo-, Oxoperoxo-, and Oxodiperoxo Molybdenum(VI) and Tungsten(VI) Compounds Containing Monodentate or Bidentate Phosphine Oxide Ligands. Inorg. Chem. 2006, 45, 1039110402.

(16) Müller, A.; Serain, C. Soluble Molybdenum Blues "des Pudels Kern”. Acc. Chem. Res. 2000, 33, 2-10.

(17) Müller, A.; Meyer, J.; Krickemeyer, E.; Diemann, E. Molybdenum Blue: A 200 Year Old Mystery Unveiled. Angew. Chem. Int. Ed. 1996, 35, 1206-1208.

(18) Huo, J.; Li, Q. Determination of thiamazole in pharmaceutical samples by phosphorus molybdenum blue spectrophotometry. Spectrochimica Acta A 2012, 87, 293-297. 
(19) Belton, D. J.; Deschaume, O.; Patwardhan, S. V.; Perry, C. C. A solution study of silica condensation and speciation with relevance to in vitro investigations of biosilicification. J. Phys. Chem. B 2010, 114, 9947-9955.

(20) Nakatani, N.; Kozika, D.; Masuda, W.; Nakagoshi, N.; Hasebe, K.; Mori, M.; Tanaka, K. Simultaneous spectrophotometric determination of phosphate and silicate ions in river water by using ion-exclusion chromatographic separation and post-column derivatization. Analytica Chimica Acta 2008, 619, 110-114.

(21) Miras, H. N.; Richmond, C. J.; Long, D.-L.; Cronin, L. Solution-phase monitoring of the structural evolution of a molybdenum blue nanoring. J. Am. Chem. Soc. 2012, 134, 3816-3824.

(22) De Saint Laumer, J.-Y.; Cicchetti, E.; Merle, P.; Egger, J.; Chaintreau, A. Quantification in gas chromatography: prediction of flame ionization detector response factors from combustion enthalpies and molecular structures. Anal. Chem. 2010, 82, 6457-6462.

(23) Gaussian 03, Revision E.01, Frisch, M. J.; Trucks, G. W.; Schlegel, H. B.; Scuseria, G. E.; Robb, M. A.; Cheeseman, J. R.; Montgomery Jr., J. A.; Vreven, T.; Kudin, Burant, J. C. et al. Gaussian, Inc., Wallingford CT, 2007.

(24) (a) Becke, A. D. Density $\square$ functional thermochemistry. I. The effect of the exchange $\square$ only gradient correction. J. Chem. Phys. 1992, 96, 2155-2160. (b) Becke, A. D. 
Density $\square$ functional thermochemistry. III. The role of exact exchange. J. Chem. Phys. 1993, 98, 5648-5652. (c) Lee, C.; Yang, W.; Parr, R. G. Development of the Colle-Salvetti correlationenergy formula into a functional of the electron density. Phys. Rev. B 1988, 37, 785-789.

(25) Hay, P. J.; Wadt, W. R. Ab initio effective core potentials for molecular calculations. Potentials for K to Au including the outermost core orbitals. J. Chem. Phys. 1985, 82, 270-283.

(26) Ehlers, A. W.; Boehme, M.; Dapprich, M.; Gobbi, A.; Hoellwarth, A.; Jonas, V.; Koehler, K. F.; Stegmann, R.; Veldkamp, A.; Frenking, G. A set of f-polarization functions for pseudo-potential basis sets of the transition metals $\mathrm{Sc}-\mathrm{Cu}, \mathrm{Y}-\mathrm{Ag}$ and $\mathrm{La}-\mathrm{Au}$. Chem. Phys. Lett. 1993, 208, 111-114.

(27) Liu, T.; Diemann, E.; Li, H.; Dress, A. W. M.; Muller, A. Self-assembly in aqueous solution of wheel-shaped Mo154 oxide clusters into vesicles. Nature 2003, 426, 59-62.

(28) Muller, A.; Diemann, E.; Kuhlmann, C.; Eimer, W.; Serain, C.; Tak, T.; Knochel, A.; Pranzas, P. K. Hierarchic patterning: architectures beyond 'giant molecular wheels'. Chem. Commun. 2001, 1928-1929.

(29) Trost, B. M.; Masuyama, Y. Chemoselectivity in molybdenum catalyzed alcohol and aldehyde oxidations. Tet. Lett. 1984, 25, 173-176.

(30) Hermans, I.; Jacobs, P.; Peeters, J. The formation of byproducts in the autoxidation of cyclohexane. Chem. Eur. J. 2007, 13, 754-761.

(31) Musser, M. T. Ullmann's Encyclopedia of Industrial Chemistry Cyclohexanol and Cyclohexanone; Wiley-VCH: Weinheim, Germany, 2011. 
(32) Sheldon, R. A.; van Doorn, J. A. Metal-catalyzed epoxidation of olefins with organic hydroperoxides: I. A comparison of various metal catalysts. J. Catal. 1973, 31, 427-437.

(33) Bagherzadeh, M.; Amini, M.; Ellern, A.; Woo, L. K. Catalytic efficiency of a novel complex of oxoperoxo molybdenum (VI): Synthesis, X-ray structure and alkane oxidation. Inorg. Chem. Comm. 2012, 15, 52-55.

(34) Wahlen, J.; De Vos, D. E.; Groothaert, M. H.; Nardello, V.; Aubry, J.-M.; Alsters, P. L.; Jacobs, P. A. Synergism between molybdenum and lanthanum in the disproportionation of hydrogen peroxide into singlet oxygen. J. Am. Chem. Soc. 2005, 127, 17116-17117.

(35) Biradar, A. V.; Dongare, M. K.; Umbarkar, S. B. Selective oxidation of aromatic primary alcohols to aldehydes using molybdenum acetylide oxo-peroxo complex as catalyst. Tet. Lett. 2009, 50, 2885-2888.

(36) Indeed, we calculate the proposed reaction via $\eta^{1}-\mathrm{OOH}$ precursor to have an adiabatic barrier of $42 \mathrm{kcal} \mathrm{mol}^{-1}$, i.e. it is disfavored by $24 \mathrm{kcal} \mathrm{mol}^{-1}$, with respect to $\mathbf{T S}_{\mathbf{2}-3}$.

(37) (a) Bohme, D. K.; Schwarz, H. Gas-Phase Catalysis by Atomic and Cluster Metal Ions: The Ultimate Single-Site Catalysts. Angew. Chem. Int. Ed. 2005, 44, 2336-2354. (b) Spier, E.; Neuenschwander, U.; Hermans, I. Insights into the Cobalt (II) $\square$ Catalyzed Decomposition of Peroxide. Angew. Chem. Int. Ed. 2013, 52, 1581-1585.

(38) Based on a comproportionation of $\mathrm{K}=500 \mathrm{M}^{-1}$, occuring with a rate constant of $1470 \mathrm{M}^{-1}$ $\mathrm{s}^{-1}$, and a typical dimerisation entropy of $36 \mathrm{cal} \mathrm{K}^{-1} \mathrm{~mol}^{-1}$. (a) Fortner, K. C.; Laitar, D. S.; Muldoon, J.; Pu, L.; Braun-Sand, S. B.; Wiest, O.; Brown, S. N. Ultrafast and ultraslow oxygen atom transfer reactions between late metal centers. J. Am. Chem. Soc. 2007, 129, 588-600. (b) 
Chocholousova, J.; Vacek, J.; Hobza, P. Acetic Acid Dimer in the Gas Phase, Nonpolar Solvent, Microhydrated Environment, and Dilute and Concentrated Acetic Acid: Ab Initio Quantum Chemical and Molecular Dynamics Simulations. J. Phys. Chem. A 2003, 107, 3086-3092.

(39) Zhu, L.; Bozzelli, J. W.; Kardos, L. M. Thermochemical Properties, $\Delta \mathrm{fH}^{\circ}(298), \mathrm{S}^{\circ}(298)$, and $\mathrm{Cp}^{\circ}(\mathrm{T})$, for n-Butyl and n-Pentyl Hydroperoxides and the Alkyl and Peroxy Radicals, Transition States, and Kinetics for Intramolecular Hydrogen Shift Reactions of the Peroxy Radicals. J. Phys. Chem. A 2007, 111, 6361-6377.

(40) Buckley, R. I.; Clark, R. J. H. Structural and electronic properties of some polymolybdates reducible to molybdenum blues. Coord. Chem. Rev. 1985, 65, 167-218.

(41) Palopoli, C.; Gonzalez-Sierra, M.; Robles, G.; Dahan, F.; Tuchagues, J.-P.; Signorella, S. Synthesis and characterisation of dimanganese(III) complexes of 1,5-bis(Xsalicylidenamino)pentan-3-ol ( $\mathrm{X}=3$ - or 5-methoxy) and their catalytic activity towards hydrogen peroxide disproportionation. J. Chem. Soc. Dalton Trans. 2002, 3813-3819.

(42) For a case where such modeling was possible, thanks to many available observables, see: Neuenschwander, U.; Meier, E.; Hermans, I. Peculiarities of $\beta \square$ Pinene Autoxidation. ChemSusChem 2011, 4, 1613-1621.

(43) Amini, M.; Haghdoost, M. M.; Bagherzadeh, M. Oxido-peroxido molybdenum(VI) complexes in catalytic and stoichiometric oxidations. Coord. Chem. Rev. 2013, 257, 1093-1121.

(44) Analogous homolytic behavior of XOOOR species $(\mathrm{R}=\{\mathrm{H}$, alkyl $\})$ was described for $\mathrm{X}=\{\mathrm{H}, \mathrm{Al}, \mathrm{Ti}, \mathrm{Zr}, \mathrm{V}\}$. See (a) Pryor, W. A.; Ohto, N.; Church, D. F. Reaction of cumene with ozone to form cumyl hydrotrioxide and the kinetics of decomposition of cumyl hydrotrioxide. $J$. 
Am. Chem. Soc. 1983, 105, 3614-3622. (b) Stepovik, L. P.; Gulenova, M. V.; Martynova, I. M. Titanium(IV) tert-Butoxide-tert-Butyl Hydroperoxide System as Oxidant for C-H Bonds in Hydrocarbons and Oxygen-containing Compounds. Russ. J. Gen. Chem. 2005, 75, 507-513. (c) Stepovik, L. P.; Martinova, I. M.; Dodonov, V. A.; Cherkasov, V. K. ESR study of the thermal decomposition of di-tert-butoxy-tert-butyl alumotrioxide formed in the reaction of tri-tertbutoxyaluminum with tert-butyl hydroperoxide. Russ. Chem. Bull. Int. Ed. 2002, 51, 638-644. (d) Gulenova, M. V.; Stepovik, L. P.; Cherkasov, V. K. Reaction of zirconium alkoxides with

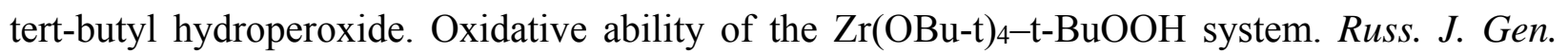
Chem. 2006, 76, 980-988. (e) Stepovik, L. P.; Gulenova, M. V. Specific features of the reaction of vanadyl acetylacetonate with tert-butyl hydroperoxide. Russ. J. Gen. Chem. 2009, 79, 16631670.

(45) Estimation of the unimolecular dissociation rate constant: $k 7-8=10^{15} \exp \left(-19 \mathrm{kcal} \mathrm{mol}^{-1}\right)$.

(46) Turra, N.; Neuenschwander, U.; Hermans, I. Mechanism of the Catalytic Deperoxidation of tert $\square$ Butylhydroperoxide with Cobalt (II) Acetylacetonate. Chem. Eur. J. 2010, 16, 1322613235.

(47) Stone, D.; Rowley, D. M. Kinetics of the gas phase $\mathrm{HO}_{2}$ self-reaction: effects of temperature, pressure, water and methanol vapours. Phys. Chem. Chem. Phys. 2005, 7, 21562163. 


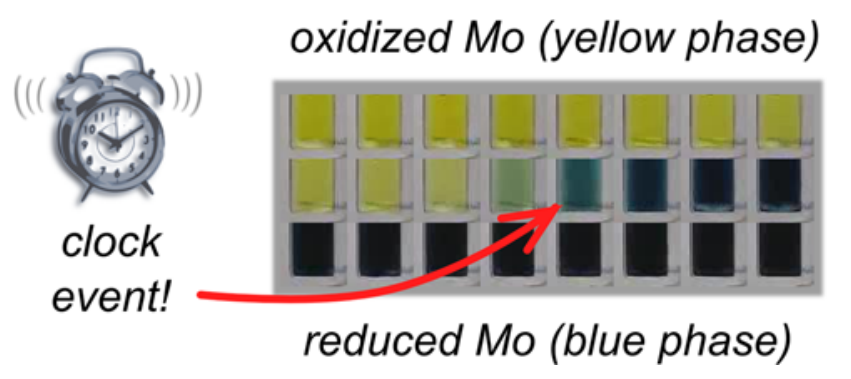




\section{Supporting Information}

\section{A Clock Reaction Based on Molybdenum Blue}

Ulrich Neuenschwander, Arnaldo Negron, Klavs F. Jensen*

Department of Chemical Engineering, Massachusetts Institute of Technology, 77 Massachusetts Avenue, Cambridge MA 02139, USA.

*kfjensen@mit.edu

\section{Contents}

cartesian coordinates of optimized intermediates .......................................... 22

cartesian coordinates of optimized transition states .......................................... S4

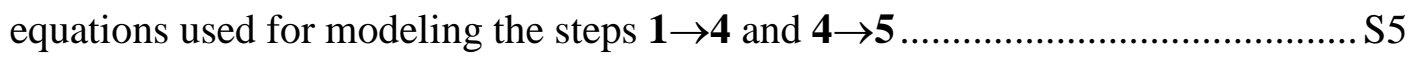

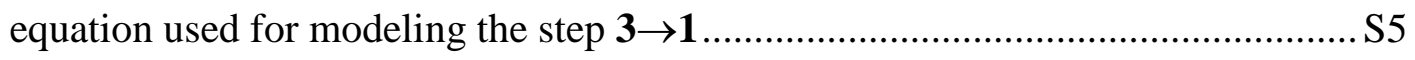

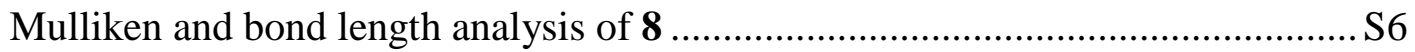




\section{Cartesian coordinates of optimized intermediates}

1

$\begin{array}{ccrr}\text { Mo } & -0.00000 & -0.29202 & 0.00000 \\ \text { O } & 1.43450 & 0.77474 & -0.54242 \\ \text { C } & 2.70584 & 1.09001 & 0.01481 \\ \text { H } & 2.70166 & 2.13209 & 0.35201 \\ \text { H } & 2.94006 & 0.43492 & 0.86128 \\ \text { H } & 3.46707 & 0.96758 & -0.76225 \\ \text { O } & 0.49652 & -1.26749 & 1.29495 \\ \text { O } & -0.49650 & -1.26755 & -1.29492 \\ \text { O } & -1.43450 & 0.77475 & 0.54240 \\ \text { C } & -2.70584 & 1.09001 & -0.01483 \\ \text { H } & -3.46706 & 0.96766 & 0.76226 \\ \text { H } & -2.70165 & 2.13206 & -0.35211 \\ \text { H } & -2.94010 & 0.43487 & -0.86125\end{array}$

2

$\begin{array}{crrr}\text { Mo } & 0.04558 & -0.19362 & 0.15509 \\ \mathrm{O} & -1.15716 & 1.23497 & 0.25639 \\ \mathrm{C} & -2.44277 & 1.49013 & -0.28666 \\ \mathrm{H} & -2.42251 & 2.47260 & -0.77057 \\ \mathrm{H} & -2.71456 & 0.72566 & -1.02252 \\ \mathrm{H} & -3.17977 & 1.50073 & 0.52311 \\ \mathrm{O} & -1.38051 & -1.24750 & -0.60310 \\ \mathrm{O} & 0.40920 & -0.54238 & 1.75727 \\ \mathrm{O} & 1.51360 & 0.55749 & -0.71819 \\ \mathrm{C} & 2.82152 & 0.99167 & -0.36219 \\ \mathrm{H} & 3.54323 & 0.49696 & -1.01965 \\ \mathrm{H} & 2.88280 & 2.07450 & -0.51350 \\ \mathrm{H} & 3.05056 & 0.75463 & 0.68223 \\ \mathrm{O} & -0.05344 & -1.85055 & -0.75481\end{array}$

3

$\begin{array}{cccc}\text { Mo } & 0.325860 & -0.064476 & 0.000070 \\ \text { O } & 1.259612 & 1.560988 & 0.223259 \\ \text { O } & 0.256417 & -0.870078 & 1.486337 \\ \text { O } & -1.411987 & 0.266984 & -0.580589 \\ \text { C } & -2.706107 & 0.174612 & 0.007050 \\ \text { H } & -3.344260 & -0.427767 & -0.647013 \\ \text { H } & -2.656790 & -0.288502 & 0.998585 \\ \text { H } & -3.127570 & 1.181264 & 0.094888 \\ \text { H } & 1.927476 & 1.842061 & -0.417515 \\ \text { O } & 1.114919 & -1.038734 & -1.138282\end{array}$

4

$\begin{array}{ccrr}\text { Mo } & -0.138971 & -0.003654 & 0.345599 \\ \text { O } & -1.848652 & 0.586114 & -0.115635 \\ \text { C } & -2.815293 & 0.259586 & -1.087298 \\ \text { H } & -3.795142 & 0.598146 & -0.735694 \\ \text { H } & -2.579123 & 0.757415 & -2.036229 \\ \text { H } & -2.823786 & -0.827097 & -1.233246 \\ \text { O } & -0.910069 & -1.718784 & -0.159989 \\ \text { O } & -0.052188 & 0.28762 & 1.99895 \\ \text { O } & 0.649975 & 1.386321 & -0.678303 \\ \text { C } & 1.918869 & 1.997893 & -0.518208 \\ \text { H } & 2.679022 & 1.248042 & -0.264784 \\ \text { H } & 2.189987 & 2.490824 & -1.457993 \\ \text { H } & 1.882282 & 2.746379 & 0.28269 \\ \text { H } & -0.335349 & -2.47528 & 0.02023 \\ \text { C } & 2.068835 & -1.580626 & -0.93847 \\ \text { H } & 2.245887 & -0.863426 & -1.752163 \\ \text { H } & 3.017748 & -2.051002 & -0.659788 \\ \text { H } & 1.386771 & -2.356245 & -1.316838 \\ \text { O } & 1.527688 & -0.938199 & 0.192789\end{array}$


5

$\begin{array}{cccr}\text { Mo } & -0.501523 & 0.19697 & -0.176859 \\ \mathrm{O} & -1.654853 & -1.746611 & 0.536139 \\ \mathrm{O} & 1.265164 & -0.738151 & -0.462149 \\ \mathrm{O} & -1.168756 & 0.889682 & 1.51549 \\ \mathrm{O} & -1.39414 & 0.121456 & -1.612442 \\ \mathrm{O} & 0.639033 & 1.77155 & -0.300447 \\ \mathrm{C} & 0.09947 & 3.065055 & -0.119232 \\ \mathrm{H} & 0.922414 & 3.788287 & -0.029534 \\ \mathrm{H} & -0.518046 & 3.361162 & -0.981303 \\ \mathrm{H} & -0.521299 & 3.120267 & 0.785776 \\ \mathrm{C} & -3.050667 & -1.821456 & 0.170079 \\ \mathrm{H} & -3.472067 & -2.779792 & 0.488842 \\ \mathrm{H} & -3.554457 & -1.012689 & 0.700835 \\ \mathrm{H} & -3.173638 & -1.670759 & -0.905462 \\ \mathrm{C} & 2.404604 & -0.811301 & 0.061917 \\ \mathrm{H} & -1.887991 & 0.378745 & 1.912651 \\ \mathrm{H} & -1.189313 & -2.476831 & 0.108324 \\ \mathrm{C} & 2.633426 & -0.268467 & 1.442515 \\ \mathrm{H} & 2.05022 & -0.846727 & 2.174419 \\ \mathrm{H} & 3.685936 & -0.309829 & 1.731064 \\ \mathrm{H} & 2.274096 & 0.76478 & 1.486318 \\ \mathrm{C} & 3.506691 & -1.494192 & -0.692492 \\ \mathrm{H} & 3.900558 & -2.348887 & -0.125653 \\ \mathrm{H} & 3.147394 & -1.836586 & -1.664323 \\ \mathrm{H} & 4.347436 & -0.805114 & -0.843343\end{array}$

7

$\begin{array}{cccc}\text { Mo } & 0.539705 & -0.514603 & -0.244099 \\ \mathrm{O} & -0.660728 & 1.657134 & -0.064366 \\ \mathrm{O} & -1.353431 & -1.114861 & -0.461213 \\ \mathrm{C} & -0.605065 & 2.610317 & -1.137527 \\ \mathrm{H} & -1.117246 & 3.53299 & -0.844602 \\ \mathrm{H} & 0.446905 & 2.816893 & -1.329193 \\ \mathrm{H} & -1.053976 & 2.20945 & -2.052163 \\ \mathrm{O} & 1.17561 & 0.06922 & 1.409536 \\ \mathrm{O} & 1.22347 & 0.309576 & -1.556828 \\ \mathrm{O} & 1.13252 & -2.093893 & -0.351013 \\ \mathrm{O} & -2.440324 & -0.284085 & -0.058452 \\ \mathrm{H} & -1.581435 & 1.365367 & 0.053572 \\ \mathrm{O} & -2.605131 & -0.450628 & 1.359306 \\ \mathrm{H} & -3.007561 & -1.33756 & 1.398625 \\ \mathrm{C} & 1.678162 & 1.300006 & 1.913441 \\ \mathrm{H} & 2.620344 & 1.555093 & 1.415537 \\ \mathrm{H} & 0.948557 & 2.099188 & 1.754878 \\ \mathrm{H} & 1.862347 & 1.170291 & 2.98426\end{array}$

8

$\begin{array}{crrr}\text { Mo } & -0.561625 & -0.296855 & 0.03824 \\ \mathrm{O} & 1.916328 & 0.248393 & -0.460014 \\ \mathrm{O} & 0.327802 & -1.378771 & -1.221267 \\ \mathrm{C} & 2.924757 & -0.400645 & 0.339262 \\ \mathrm{H} & 3.885184 & 0.109036 & 0.208335 \\ \mathrm{H} & 2.593063 & -0.320212 & 1.37318 \\ \mathrm{H} & 3.018275 & -1.456162 & 0.06908 \\ \mathrm{O} & -0.758011 & 1.50283 & -0.440707 \\ \mathrm{O} & 0.047229 & -0.486871 & 1.613795 \\ \mathrm{O} & -2.117418 & -0.987024 & -0.024918 \\ \mathrm{H} & 2.067644 & 0.042854 & -1.394015 \\ \mathrm{C} & -0.144945 & 2.706166 & 0.004733 \\ \mathrm{H} & 0.945581 & 2.610094 & -0.004883 \\ \mathrm{H} & -0.446602 & 3.509244 & -0.67519 \\ \mathrm{H} & -0.481215 & 2.95149 & 1.018347\end{array}$




\section{Cartesian coordinates of optimized transition states}

$\begin{array}{ccccc}\text { TS }_{2-3} & \text { Mo } & 0.64924800 & -0.35279200 & 0.04490900 \\ & \text { O } & -0.92646500 & 0.71708400 & 0.51393800 \\ \text { C } & -2.15116900 & 0.36868200 & 0.01235000 \\ \text { H } & -1.91834000 & -0.64145800 & -0.64956900 \\ \text { O } & -0.78623700 & -1.25565800 & -0.96092100 \\ \text { O } & 1.09159200 & -0.91205600 & 1.57269200 \\ \text { O } & 1.76999100 & 1.02795700 & -0.52237500 \\ \text { C } & 2.62181800 & 1.95625900 & 0.13871100 \\ \text { H } & 3.43510400 & 2.22038900 & -0.54410400 \\ \text { H } & 2.05288400 & 2.85938200 & 0.38659100 \\ \text { H } & 3.03892100 & 1.52684300 & 1.05620100 \\ \text { O } & 0.93617000 & -1.71162700 & -1.08890400 \\ \text { C } & -3.12196300 & -0.08359000 & 1.09354200 \\ \text { H } & -3.37572700 & 0.77207600 & 1.73058800 \\ \text { H } & -4.04415700 & -0.47553300 & 0.65601800 \\ \text { H } & -2.66550500 & -0.85316500 & 1.72030600 \\ \text { C } & -2.68523000 & 1.36305500 & -1.00951800 \\ \text { H } & -3.60464400 & 0.99465800 & -1.47229100 \\ \text { H } & -2.90530400 & 2.31221400 & -0.50681100 \\ \text { H } & -1.94280000 & 1.54980300 & -1.78905800\end{array}$

$\begin{array}{ccccc}\text { TS }_{4-5} & \text { Mo } & -0.56268900 & -0.38331900 & -0.24300400 \\ & \text { O } & -1.95735500 & 0.80193700 & 0.34806600 \\ \text { C } & -3.26898400 & 0.40622100 & 0.72518800 \\ \text { H } & -3.23983300 & -0.45431000 & 1.40195100 \\ \text { H } & -3.75128600 & 1.25315500 & 1.22780600 \\ \text { H } & -3.86037700 & 0.13962900 & -0.16125800 \\ \text { O } & -0.98745400 & -0.91685700 & -1.77747100 \\ \text { O } & 0.46626000 & 1.38792600 & -0.41539000 \\ \text { O } & 1.30520700 & -0.82288800 & -0.05942300 \\ \text { C } & 2.39960000 & -0.09584800 & 0.21739100 \\ \text { H } & 1.55365500 & 1.10767700 & -0.22599000 \\ \text { O } & -1.24638300 & -1.59604300 & 1.09338600 \\ \text { C } & 0.11660400 & 2.76271300 & -0.23865600 \\ \text { H } & 0.37585500 & 3.32403100 & -1.14140400 \\ \text { H } & -0.95991100 & 2.79252500 & -0.06180700 \\ \text { H } & 0.64766700 & 3.17814700 & 0.62405500 \\ \text { H } & -0.75004500 & -2.42442500 & 1.15578200 \\ \text { C } & 2.67016600 & 0.16462900 & 1.68821200 \\ \text { H } & 3.41999600 & 0.95203300 & 1.81115500 \\ \text { H } & 1.75934500 & 0.46587700 & 2.21564700 \\ \text { H } & 3.05762000 & -0.73877500 & 2.18331300 \\ \text { C } & 3.58928500 & -0.39103900 & -0.66806200 \\ \text { H } & 4.32880800 & 0.41349700 & -0.60331800 \\ \text { H } & 4.09190000 & -1.32288100 & -0.36728700 \\ \text { H } & 3.27732000 & -0.49946700 & -1.71027600\end{array}$

$\begin{array}{rrrrr}\text { TS }_{2-7} & \text { Mo } & 0.44554900 & -0.35972400 & -0.20758600 \\ & \text { O } & -0.66233500 & 1.30028800 & -0.07756300 \\ \text { O } & -1.39144500 & -1.12116000 & -0.11774800 \\ \text { C } & -0.15855700 & 2.57456800 & -0.47175100 \\ \text { H } & -0.95243600 & 3.31676500 & -0.34190900 \\ \text { H } & 0.69344900 & 2.85764000 & 0.15686800 \\ \text { H } & 0.16007100 & 2.55986200 & -1.52097600 \\ \text { O } & 1.67551000 & 0.08457900 & 1.12294400 \\ \text { O } & 1.16298600 & -0.10394800 & -1.71324000 \\ \text { O } & 0.18235100 & -2.10230300 & -0.05810700 \\ \text { O } & -2.76050500 & 0.11081600 & -0.15968000 \\ \text { H } & -2.01008000 & 0.84358200 & -0.12139900 \\ \text { O } & -3.28020200 & 0.16278400 & 1.17275100 \\ \text { H } & -3.59451200 & -0.75356600 & 1.25903000 \\ \text { C } & 3.05163300 & 0.43572700 & 1.18614400 \\ \text { H } & 3.44709400 & 0.67237300 & 0.19213800 \\ \text { H } & 3.16161600 & 1.30510200 & 1.84253600 \\ \text { H } & 3.61240000 & -0.40355800 & 1.61110900\end{array}$




\section{Equations used for modeling the steps $1 \rightarrow 4$ and $4 \rightarrow 5$}

For MB formation, $\mathbf{4} \rightarrow \mathbf{5}$ is the most important reaction. However, first $\mathbf{4}$ needs to be made from $\mathbf{1}$, a reaction which is reversible. Since $\mathbf{1} \rightarrow \mathbf{4}$ is calculated to be thermoneutral and is isentropic under fixed solvation shell conditions, it can be roughly assumed that $K_{1-4} \approx 1$. As $\mathrm{ROH}$ is the solvent, its concentration can be directly included in the equilibrium constant (equation S1). Instead of modeling this equilibrium dynamically, we assumed fast equilibration and thus expressed the overall rate of reaction $\mathbf{4} \rightarrow \mathbf{5}$ as a function of [1] (equation S4).

The subtle distinction of the reactive part of the [1] pool (i.e. [4]) and the unreactive part of the [1] pool (i.e. [ $\left.\mathbf{1}_{\mathrm{nr}}\right]$ ) is only relevant for this case, due to the quantum chemically found lowering of the barrier by solvolysis. The other elementary steps are most likely not affected by the catalyst being in state $\mathbf{4}$ or $\mathbf{1}_{\mathrm{nr}}$, and therefore we opted for the simple notation given in Table 1 .

Furthermore, treating $\mathbf{1}$ by lumping together $\mathbf{1}_{\text {nr }}$ and $\mathbf{4}$ keeps the model complexity at a reasonable level.

$\begin{array}{lll}\text { Equilibrium } & {[\mathbf{4}]=K_{1-4}^{\prime}[\mathrm{ROH}]\left[\mathbf{1}_{\mathrm{nr}}\right]=K_{1-4}\left[\mathbf{1}_{\mathrm{nr}}\right]} \\ \text { Distinction } & {\left[\mathbf{1}_{\mathrm{nr}}\right]+[\mathbf{4}]=[\mathbf{1}]} \\ (\mathrm{S} 1 \mathrm{in} \mathrm{S} 2) & {[\mathbf{4}]\left(1+K_{1-4}^{-1}\right)=[\mathbf{1}]} \\ & {[\mathbf{4}]=\left(1+K_{1-4}-^{-1}\right)^{-1}[\mathbf{1}]} & \text { (eq. S1) } \\ \text { Rate } & r_{4-5}=k_{4-5}[\mathbf{4}]=k_{4-5}\left(1+K_{1-4}^{-1}\right)^{-1}[\mathbf{1}]\end{array}$

\section{Equation used for modeling the step $3 \rightarrow 1$}

Reaction $\mathbf{3} \rightarrow \mathbf{1}$ is a mere solvent coordination event and supposedly very fast, compared to the other steps in the catalytic cycle. Thus, in the kinetic model we directly substituted any formation of $\mathbf{3}$ by quasi instantaneous formation of $\mathbf{1}$.

Substitution $\quad \mathrm{d}[\mathbf{1}] / \mathrm{d} t=\mathrm{d}[\mathbf{3}] / \mathrm{d} t$

(eq. S5) 


\section{Mulliken and bond length analysis of 8}

The electronic configuration of $\mathbf{8}$ was invesigated by Mulliken and bond length analysis (Figure S1). Both bond lenghts and Mulliken spin densities consistently revealed a structure that is best described by a localized oxyl radical rather than a mesomerically diffuse form.

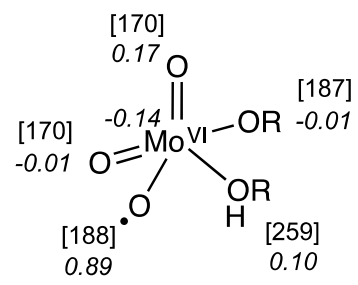

Figure S1. Bond lengths to ligands (square brackets, in pm) and Mulliken spin densities (italic, atomic units) on Mo and $\mathrm{O}$ atoms in the $\mathrm{Mo}^{\mathrm{VI}}$ oxyl species 8. 